\title{
A Review on Human Orf: A Neglected Viral Zoonosis
}

\section{Tesfaye Kassa $\mathbb{D}$}

School of Medical Laboratory Science, Institute of Health, Jimma University, Jimma, Ethiopia
Correspondence: Tesfaye Kassa Jimma University, PO Box 6 788, Jimma, Ethiopia

Tel +251931057195

Email ktes36@gmail.com;
Abstract: Orf virus (ORFV) is the etiologic agent of Orf or ecthyma contagiosum in humans but primarily affects different domestic and wild animals. The disease mostly affects sheep, goats and other small wild ruminants and spreads to humans through direct contact with infected animals or by way of contaminated fomites worldwide. ORFV is taxonomically classified as a member of the genus Parapoxvirus. It is known to have tolerance to inactivation in a drier environment, and it has been recovered from crusts after several months to years. Among immunocompetent people, the lesions usually resolve by its natural course within a maximum of 8 weeks. In immunosuppressed patients, however, it needs the use of various approaches including antiviral, immune modifier or minor surgical excisions. The virus through its association with divergent host ranges helps to develop a mechanism to evade the immune system. The relative emergence of Orf, diagnosed on clinical ground among human cases, in unusual frequencies in southwest Ethiopia between October 2019 and May 2020, was the driver to write this review. The objective was to increase health care providers' diagnostic curiosity and to bring the attentiveness of public health advisors for prevention, control and the development of schemes for surveillance of Orf zoonosis in a similar setting like Ethiopia.

Keywords: Orf, Orf virus, ecthyma contagiosum, zoonosis, human, Ethiopia

\section{Background}

Orf or ecthyma contagiosum (EC) is primarily a zoonosis affecting the skin of humans. ${ }^{1}$ The disease is caused by Orf virus (ORFV) which is a member of the genus Parapoxvirus. ${ }^{2}$ The virus is communicable to humans from infected small ruminants predominantly sheep and goats. Less commonly, it has been described transmissible from contaminated fomites and environments besides a rare humanto-human transmission or auto-infection has also been defined. ${ }^{3}$

ORFV has a worldwide endemicity among livestock herds. ${ }^{1,4}$ The virus manifests among infected animals as proliferative skin or mucous membrane lesions named ecthyma contagiosum, contagious pustular dermatitis, infectious labial dermatitis, scabby mouth, or sore mouth with the lesions often appearing on the parts of lips, muzzle, ears, eyelids, nostrils, and, less commonly in udders, genitalia, and feet of the infected animals. ${ }^{5,6}$ In humans, the lesions manifest often on the exposed parts of the skin that can contact animals especially on the hands, fingers, and forearms. ${ }^{7}$

Ethiopia, in the sub-Saharan and horn of Africa region, has a sizable livestock resource, and most of them are owned by small scale farmers and pastoralists in the rural areas of the country. According to the Central Statistical Agency of Ethiopia in 2019 , the estimated count of sheep and goats are approximately 72.0 million among 
which 33.02 million and 38.96 million are sheep and goats, respectively. ${ }^{8}$ These categories of animals alone, excluding other small wild and domestic ruminants in the geographic location, can greatly increase the risk of human exposure to the virus. Also, human employment status is another known associated factor for increasing the occurrence of the infections in urban areas such as among veterinarians, slaughterhouse workers, butcher, farmworkers, zookeepers, and others. ${ }^{9-11}$ Still the largest proportion of the Ethiopian population ( $78 \%$ ) lives in rural areas on small hold farms. ${ }^{8}$

There are few published works available on the substantial morbidity of Orf or EC among animals in Ethiopia. ${ }^{12-15}$ This author searched published studies and no studies were found describing Orf or EC infections of humans in Ethiopia. Recently, a series of cases clinically suspected as Orf have been observed among patients at a dermatology clinic in Jimma University Medical Center as well as cases arising in the community in Jimma town since October 2019 until the mid of 2020. Typical clinical dermatologic appearances of the lesions were used to record suspected cases of ORFV infections despite the absence of mechanisms to confirm the virus from biopsied material (Figure 1) using histology, molecular amplification techniques, or electron microscopy. ${ }^{16,17}$ For some of the visiting cases, the base of the lesions were opened and swabbed for bacterial culture and all remained negative after one week of incubation at $37{ }^{\circ} \mathrm{C}$ (data not shown).
Thus, the objective of the current study is to provide an increased curiosity for health professionals and public health officials in Jimma, Ethiopia as well as in many other low income settings of the potential importance of this virus. Different literature sources were examined to review the disease and the virus, respectively. Furthermore, this review offers an update on clinical findings of human Orf cases in Ethiopia and equally, it may sensitize the health sectors in other African countries to consider the potential importance of this virus in their clinical settings. The information considered in this review suggests it is important to recognize orf as the disease is a common infection of ruminant animals in most parts of Africa $^{18}$ where per capita health spending is relatively low and advanced diagnostic tools are inaccessible to support diagnosis. Before the virus extends its affliction among susceptible hosts, there is a need for confirmatory diagnostic tools to rule out and employ a one health approach for epidemiologic surveillance, prevention and control of the disease.

\section{Search Methods}

A literature search was made to find published studies reporting on Orf and Orf virus with particular focus to African countries. Emphasis was given on the burden of the virus in human morbidity as well as its distribution in source animals with particular attention to sheep and goats published in the English language, mainly in recent years.
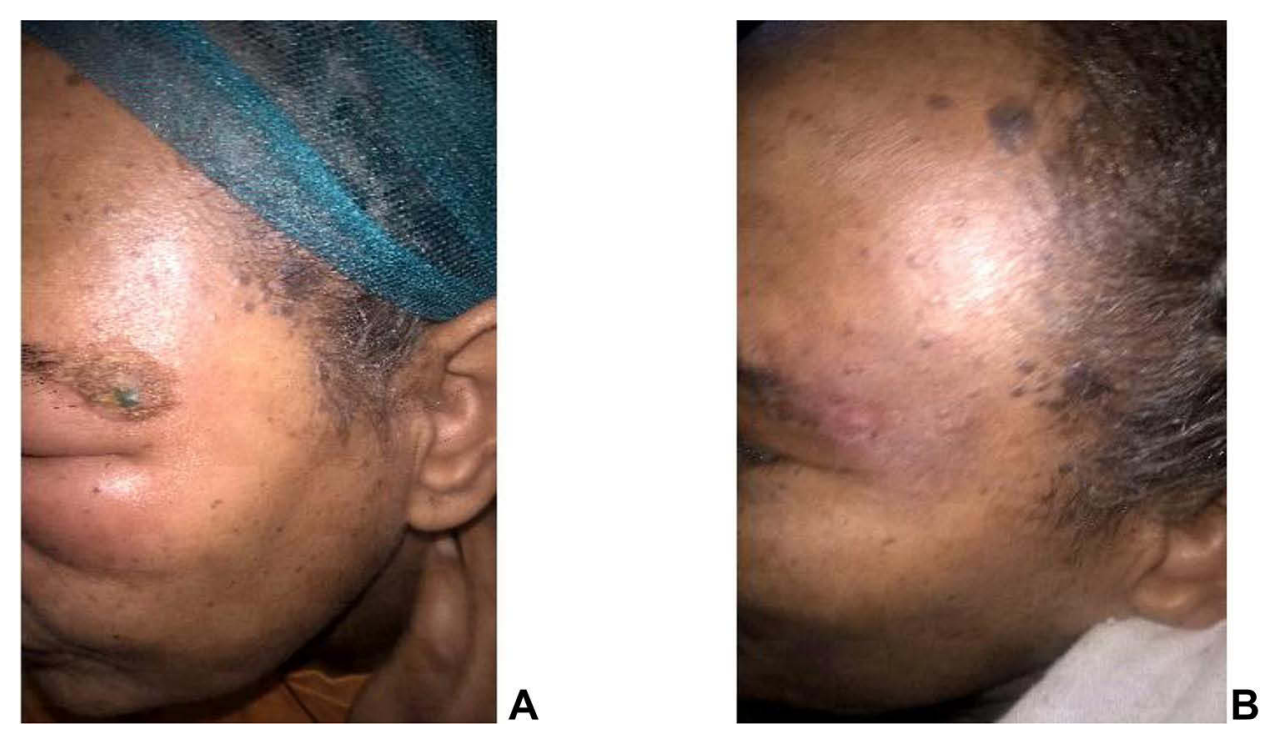

Figure I A 45 year old woman patient representative of the characteristic single Orf lesion on the second (A) and eighth (B) weeks of orf/EC appearance, from Jimma town, Ethiopia. 
The search was conducted in the electronic databases of PubMed, Google Scholar, and African journals online without time limit. The specific Medical Subject Heading (MeSH) terms individually or compounded search terms including "Orf virus" or "ORFV", "Parapoxvirus", "Ethiopia", "sub-Saharan Africa", "Africa", "African countries", "Orf", "Ecthyma contagiosum" or "Contagious ecthyma" and "human" were used. National and international conference presentations and reports on Orf and ORFV in Africa were also searched.

\section{Biology of the Virus \\ Derivation of the Word Orf}

The term orf's root is neither an abbreviation nor does it have a precise definition. Its origin in the literature is not clear, but some sources suggest it is derived from Old Norse, a North Germanic language once spoken in Scandinavia and its surrounding islands, as $h r \bar{u} f a$ : "crust on a wound, scab or boil". Another source attributes it to the Old English language orfcwealm: as orf ("cattle") + cwealm ("destruction"). ${ }^{19}$ Nevertheless, the disease "orf" is not commonly observed among cattle. The typical Orf or EC is a skin eruption that primarily affects sheep, goats and other small ruminants including gazelle. ${ }^{6}$ Later, it became well known, caused by a poxvirus member and that it can be spread to humans via contact with infected animals or possibly from their products. $^{20}$

\section{Orf Virus Structure}

ORFV belongs to the family Poxviridae that are comprised of the big animal viruses in size. ${ }^{20}$ The family has an ovoid shape and a complex internal structure including a double-stranded DNA genome. ${ }^{21}$ There are five species including ORFV in the Parapoxvirus genus that are important in animals and some of which are zoonosis to humans. ${ }^{9}$ They are Bovine papular stomatitis virus, Grey sealpox virus, Pseudocowpox virus, and Red deerpox virus [under the subfamily Chordopoxvirinae]. ${ }^{21,22}$

ORFV is the type species of the genus Parapoxvirus. ${ }^{21}$ Consequently, most of the genus features are described on the basis of a detailed understanding of ORFV. ${ }^{21,23}$ Features that have been proven to be useful in classifying these viruses as parapoxviruses include the distinctive virion morphology when viewed under electron microscopy (Figure 2), the high $\mathrm{G}+\mathrm{C}$ content of the genome and wider host ranges. Currently, further features are being

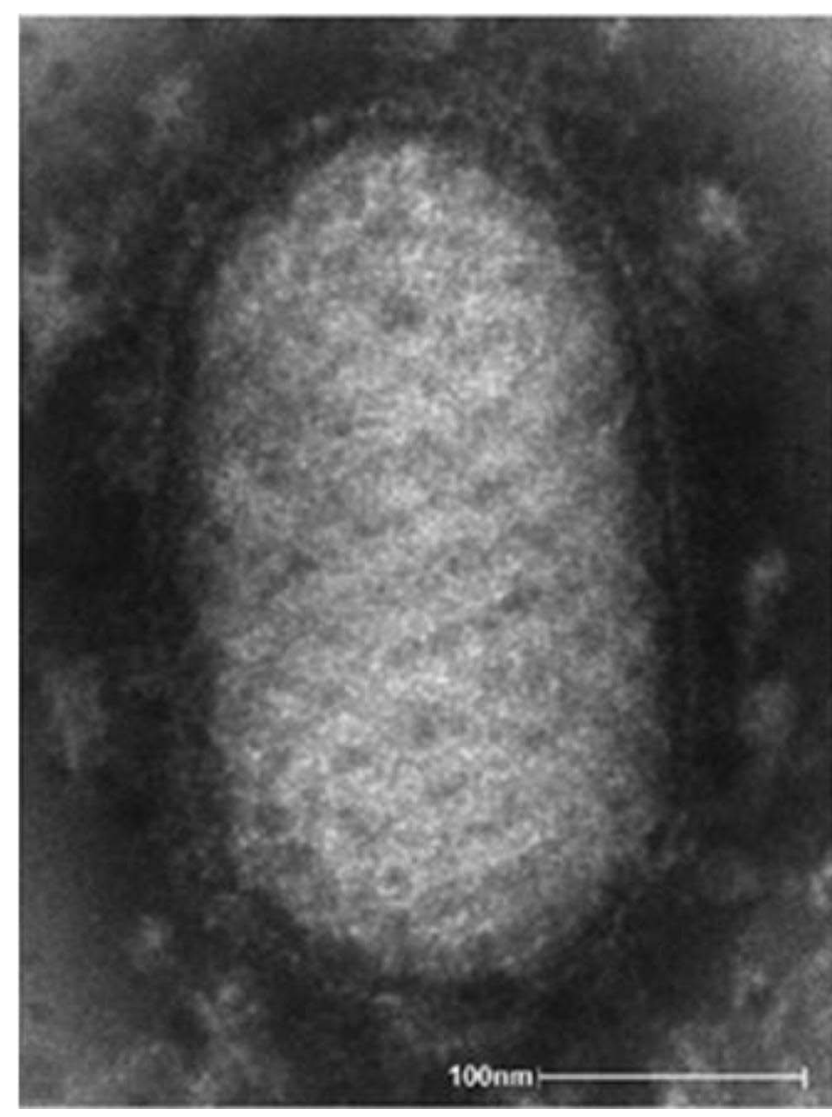

Figure 2 Negative stained electron microscopic image of ORFV.

Notes: Reproduced from Likos A, Goldsmith C. Details; Public Health Image Library (PHIL). United States Centers for Disease Control and Prevention; 2020. Available at: https://phil.cdc.gov/Details.aspx?pid=8434. Accessed November 29, $2020^{25}$

investigated to recognize the species particularly using molecular assays including DNA sequencing. The full ORFV genome has been shown to have a $64 \% \mathrm{G}+\mathrm{C}$ average nucleotide composition in contrast to most other poxviruses that have low $\mathrm{G}+\mathrm{C}$ content. $^{24}$

ORFV appears as an ovoid shaped structure with an average measurement of $295 \mathrm{~nm}$ in length by $160 \mathrm{~nm}$ in width. The Parapoxvirus that comprise ORFV can be readily identified under transmission electron microscopy by their morphology and crisscrossed tubule like structure encircling the surface of the virus particle. ${ }^{26}$ This pattern wrapping around the particle surface is genetically encoded in the virus genome. ${ }^{26-28}$ The mature ORFV particle when emerged from an infected cell after lysis appears enveloped and infectious. However, when the virions are viewed intracellularly, some of the particles appeared to possess a second wrapping membrane that originates from the Golgi apparatus and buds off the infected cell as external enveloped virion. ${ }^{23,27}$ 
ORFV, in the same manner as other poxviruses, replicates in the cytoplasm of infected host cells and therefore encodes its own machinery for DNA replication and transcription. The DNA is a linear double-stranded molecule and has a size of $134 \mathrm{~kb}$ to $140 \mathrm{~kb}$ in length. It encodes about 132 genes and is assumed to have the smallest genome length among poxvirus members. ${ }^{29,30}$ The genome consistes of a central region (Core) and inverted terminal repeats (ITR) at both ends of the DNA molecule (Figure 3). The core region of the genome encodes factors for the virus genetic transcription and replication. The transcription process is followed by the translation of different proteins for the construction of new virus particles in the cytoplasm of infected cells. Instead, the terminal regions of the ORFV genome encode for different accessory factors that also provide the parapoxvirus group many of its unique features playing a role in pathogenesis. The virus expresses about 35 virus specific proteins with molecular weights ranging between 10 and 220 $\mathrm{kDa}$ on the surface of the virus particle as a virulence factor or usable as a candidate for vaccine development since some of them are capable of inducing an immune response. $^{31}$

ORFV is not different from other poxviruses in its possession of at least two categories of genes that play roles in the virus life. These are early genes transcribed in the infection process and those transcribed in later periods (intermediate and late genes). It is doubtful whether more than one protein is produced from the early transcription of mRNAs. ${ }^{33}$ Most of the genes of ORFV in the terminal regions are unique and encode factors that play in the virus pathogenicity by modulating the immune system for the induction of inflammation, innate immune responses and the expansion of acquired immunity. ${ }^{34}$ These terminal regions of the genome typically encode other proteins that also interact with components of the immune system that also play roles in viral pathogenesis. ${ }^{29,34,35}$ These include an interleukin (IL)-10 homologue, a chemokinebinding protein (CBP), a vascular endothelial growth factor homologue (VEGF), interferon-resistance (IFNr) protein, and a cytokine-binding protein (CBP). ${ }^{36-38} \mathrm{The} \mathrm{IFNr}$ gene is present in the " $\mathrm{CORE}^{\text {ce }}$ region which is a relatively conserved one with a high $\mathrm{G}+\mathrm{C}$ content. IFNr plays a role in the viral replication and morphogenesis. ${ }^{32}$

\section{Virulence Factors}

The major virulence factors identified in ORFV as indicated above include an IL-10 homologue, CBP, VEGF homologue, granulocyte-macrophage colony-stimulating factor (GIF), apoptosis inhibitor, IFNr and inhibitors of NF- $\kappa B .{ }^{36-38}$ The discovery of an IL-10 homologue gene in a poxvirus was first reported in ORFV. ${ }^{23}$ Mammalian IL10 is a multipurpose cytokine that has suppressive effects on inflammation, anti-viral responses and T-helper type 1 (Th1) effector function. The inhibition of a Th1 response happens indirectly through abating the function of antigenpresenting macrophages and dendritic cells. ${ }^{32}$ In addition, IL-10 has co-stimulatory functions on $\mathrm{T}$ lymphocytes associated with Th2 responses, mast cells and B cells. The molecular mass of IL-10 homologue protein is 21.7 $\mathrm{kDa}$ (185 amino acids sequence) making the ORFV IL-10s slightly larger than their mammalian counterparts which is $\sim 18.6 \mathrm{kDa}$. The amino acid sequence identity of the virus IL-10 with human IL-10 is known to be $67 \%$ in the C-terminal two thirds of the polypeptide, although the relatedness at the nucleotide level is less apparent. Curiously, the N-terminal region of the IL-10 like contains little similarity to that of mammalian IL-10 23,32 and this may help to deduce that the viral IL-10 polypeptide is larger than the mammalian counterpart.

CBP is another known virulence factor among poxviruses. Normally, chemokines are a large family of

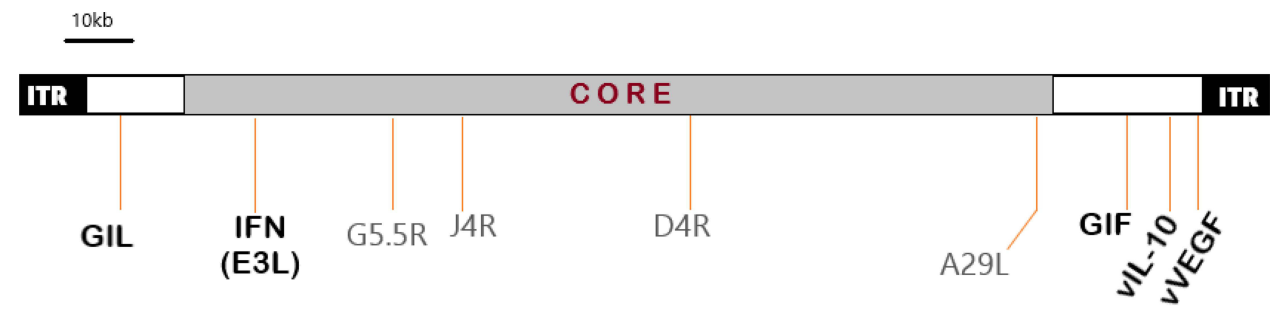

Figure 3 A representation of ORFV linear DNA molecules.

Notes: It shows the ITRs (Inverted Terminal Repeats) sequence at the ends of the genome, the central CORE region, and the terminal "non-essential" region genes (white blocks). Those parts shown in bold are genus (as well as ORFV) specific parts behaving as virulence or immuno-modulatory genes. The other genes indicated are studied as vital for poxviruses and are extremely conserved. Data from Wang and Luo. ${ }^{32}$ 
molecules that recruit and activate immune cells at sites of inflammation and infection. ${ }^{39} \mathrm{CBP}$ has been described in ORFV and is thought to interact with the chemokine families with strong affinity and results in anti-inflammatory process. ${ }^{38}$

ORFV VEGF gene encoding a polypeptide that is homologous to mammalian VEGF. The viral VEGF homologue is likely to contribute to the widespread expansion of vascular endothelial cells and enlargement of blood vessels and dermal bumps seen in typical EC lesions. The viral VEGF through its capacity to induce vascular permeability results in the development of broad scabs. This property is linked to VEGF because the lesions induced by the VEGF-gene deleted ORFV resulted in no scab formation. ${ }^{37}$ The presence of the scab affords protection of the virus from external factors knocked down in the lesions. On the other hand, the scab material which drops from Orf lesions contains an extensive number of infectious virus particles that easily contaminate different environments and contribute to the virus persistence. The virus in the process can remain viable for approximately a year retaining the capacity to infect naïve hosts. ${ }^{34}$

ORFV is unaffected by type 1 and type 2 interferon because of an IFNr factor in the virus. ${ }^{33}$ The virus also demonstrates anti-apoptosis and anti-interferon properties due to a protein called E3L. ${ }^{39}$ The NF- $\mathrm{BB}$, is a family of transcription factors that plays an essential role in directing the immune response by modifying the progression of numerous biological pathways ranging from immune regulation, inflammation, stress response to apoptosis. Inhibitors of NF- $\kappa \mathrm{B}$ encoded by ORFV help the virus to evade the host immune responses. ${ }^{40}$

GIF (protein inhibitor of Granulocyte-Macrophage Colony-Stimulating Factor and Interleukin-2) is encoded by ORFV and expressed in the late stage of the infection. It has the dual activity of inhibiting host GranulocyteMacrophage Colony-Stimulating Factor and IL-2, thus inhibiting host immune activity. ${ }^{41}$ Knowledge of the various virulence factors and the mechanism of ORFV immune evasion apparatus can be beneficial. This may direct the way to develop new and efficient vaccines or drugs to respond to the outbreaks among humans as well as in animals around the world.

\section{Transmission and Pathogenesis}

The ORFV primarily originates from skin lesions and scabs of various animals. The virus from infected animals is assumed to reach the human skin through minute cuts and abrasions. The virus is reported to remain viable on the wool and hides of animals for approximately one month after the lesions have healed. ${ }^{7}$ ORFV is very resistant to inactivation in the environment, and has been recovered from dried crusts after several months to years in the laboratory, with one account of survival recorded for up to 12 to 15 years. ${ }^{4}$ This viral property of resistance to inactivation can bring unexpected widespread public health significance among animals and humans in the future.

Humans can also become exposed to the virus by exposure to vaccines containing live ORFV that is applicable for animals. ${ }^{42}$ However, human to human transmission has not been clarified well. Most published articles do not agree with the virus transmissibility being transmissible between humans. ${ }^{43}$ While still others reported direct contact with ORFV contaminated fomites resulted in very rare cases of human infection. ${ }^{3,44}$ Nosocomial transmission has also been documented for one epidemic in the burn ward. $^{7,45}$

Once the virus reaches the skin, Orf or EC develops after a 3 to 7 days incubation period. The clinical pathology observed at the sites of infection is typically the creation of pustules and scabs. Orf lesions are normally benign; however, more serious complications can arise with secondary bacterial infections or due to misdiagnosis or over-treatment. ${ }^{1,46}$ ORFV infection in humans remains localized as foci unlike in animals where it is usually proliferative lesions. The progression of Orf from infection to resolution has been categorized sequentially into six stages each stage taking roughly one week. ${ }^{1}$

The first stage of ORFV infection is termed as the maculopapular stage which is distinguished by vacuolization of the cells of the upper epidermis. A target stage follows and is characterized by having a macroscopically visual red center bounded by a white ring of maculopapular stage cells developing, which is further encircled by a red halo of inflammation. This is followed by an acute stage where the epidermis disappears and in certain areas hair follicles are dilated and become full of pycnotic cells. In a regenerative stage in the fourth week, the epithelium is regenerating and the lesion becomes drier with a yellow crust and black center on the surface. In the fifth week, a papilloma stage is distinguished by a raised epidermal lesion with finger-like projections of epidermis extending downward into the dermis. Finally, the course enters into a regressive phase (in the sixth and later weeks) wherein the 
skin returns to its normal thickness and appearance, often without scarring. ${ }^{47}$

Since immunity against the virus is short-lived, even in immunocompetent animals or humans, reinfection can take place at a lower degree of severity, remain unnoticeable or heal quickly. ${ }^{43,48}$ Large, highly vascularized, tumor-like lesions of the skin called giant orf have been noted in immunocompromised persons. In such people, a severe progressive disease can develop and present with multiple lesions. The lesions are typically larger than usual dimensions $(>5 \mathrm{~cm})$, with multiple and recurrent lesions. ${ }^{49,50}$

\section{Clinical Features in Humans}

ORFV infection is mostly limited to the epidermal parts of the skin. Viral ecthyma or nodules typically (one to a few in number) develop on exposed parts of the human body including fingertips, hands, forearms, or face. ${ }^{51,52}$ The lesions originate as trivial papules that in due course grow into ulcerative lesions. The original lesion is a small, firm, red to blue papule at the site of ORFV entry, typically on a finger or hand. The papule develops into a hemorrhagic pustule or bulla, which can quickly produce a central crust and bleed. During later stages, the lesion transforms into a nodule that can weep fluid and leak blood, often surrounded by a thin crust and eventually, it becomes coated with a thick crust. The skin lesions may be associated with low-grade fever, which usually lasts just a few days with moderate lymphadenopathy, erythema multiforme, or lymphangitis. ${ }^{53}$

The majority of infections will be uncomplicated disorders, with the lesion usually resolving naturally within a 3 to 6 week period and sometimes can extend up to 8 weeks. Secondary bacterial infections can happen at the skin openings. Possible complications include poisonous erythema, erythema multiforme and a bullous pemphigoid-like condition; an Orf-induced immunobullous disease. ${ }^{54,55}$

Orf lesions that pass through the various pathogenesis and clinical stages generally have a dimension of greater than 1 to $3 \mathrm{~cm}$ in diameter but can rarely extend to be as big as $5 \mathrm{~cm}$. The lesions can be painful but usually resolve without the need for treatment. ${ }^{56}$

Lesions can appear as a generalized vesiculopapular rash on the skin and mucosa. ${ }^{7}$ ORFV infections rarely involve the eyes, though it has been reported to cause blindness when it emerges on the eye. ${ }^{57}$

In immunocompromised persons, giant Orf lesions can develop with continued progression in size instead of spontaneous regression. ${ }^{49,51}$ This type of lesion can take extended time or may fail to resolve naturally. In some cases, ORFV infections can cause complications such as erythema multiforme reactions and presents with rashes on the back of hands, legs and ankles. A swan-neck or a flexion of the base of index finger deformity has also been reported. ${ }^{43,49,50}$ Very rare outcomes of Orf have been described including papular and vesicular rashes and bullous pemphigoid-like eruptions. ${ }^{54}$ Most published studies showed that Orf in humans is misdiagnosed and patients are usually exposed to overtreatment and unwanted costs as can be viewed in Table 1 .

Other manifestations important for differential diagnosis in humans includes: cowpox and pseudocowpox (milker's nodule) - both are a member of poxviruses naturally affecting cattle; herpetic whitlow (caused by herpes simplex viruses); furuncle; pyoderma; pyogenic granuloma; cat scratch disease (associated with a bacterial etiology including Bartonella henselae); atypical mycobacterial infections; syphilitic chancre; deep seated fungal infections; sporotrichosis; squamous cell carcinoma; keratoacanthoma type; primary inoculation tuberculosis; tularemia; acute febrile neutrophilic dermatosis (sweet syndrome); ecthyma gangrenosum; erysipeloid (caused by Gram positive non-sporing bacilli); insect bites, or anthrax. $^{1,51,75}$ ORFV zoonotic infection shares similar clinical manifestations and exposure risks with etiologies that may have potentially life threatening outcome. As a result, suspect orf cases may necessitate the availability of confirmatory diagnostic arrangements especially in places where little or no attention has been given to this virus.

\section{Host Immune Response}

The interface of the ORFV particle with the infected host's immune system has been a subject of research for decades and most of the discoveries appear from findings in animals. ${ }^{31,75}$ Although both cell-mediated and humoral immune responses have been confirmed in sheep and human ORFV infections, cell-mediated immunity plays the major role against the virus. ${ }^{75,76}$ Antibodies do not appear to confer protective immunity to ORFV although IgG2 isotype might be important in defense against the virus. IgG2 is not transported in the milk of ruminants which might explain why colostral antibodies are not protective in lambs and kids. ${ }^{34,77}$ Since immunity against ORFV is short-lived, both animals and humans remain susceptible to reinfection. ${ }^{20,75}$ So far, there is no available protective vaccine for human use. 


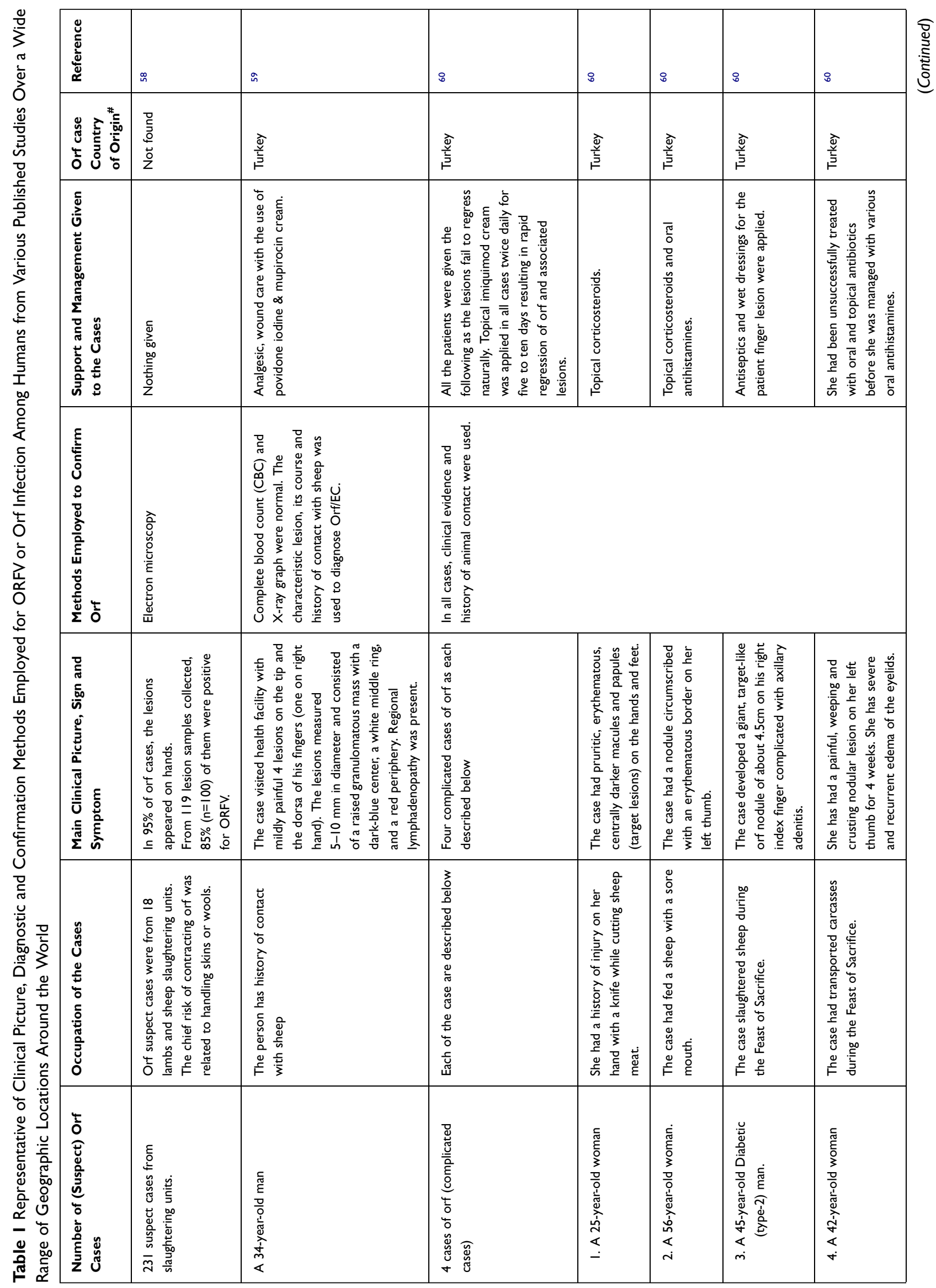




\begin{tabular}{|c|c|c|c|c|}
\hline 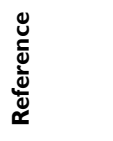 & q & $\overline{0}$ & ธิ & 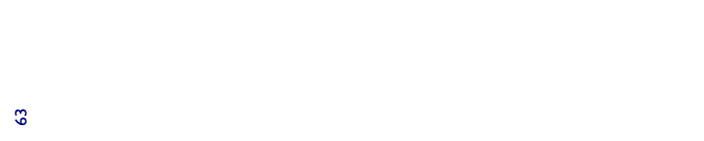 \\
\hline 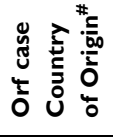 & 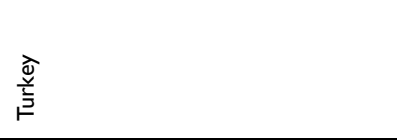 & 吕 & 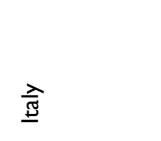 & 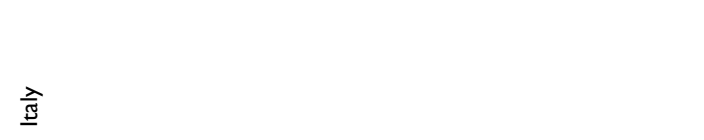 \\
\hline 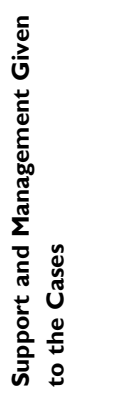 & 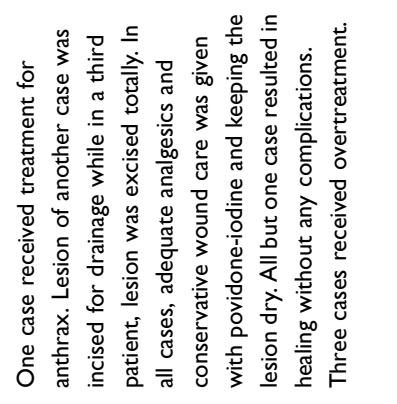 & 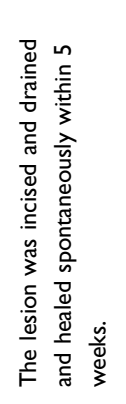 & 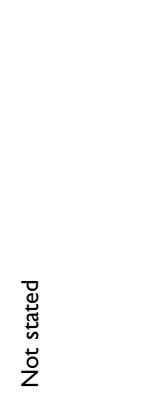 & 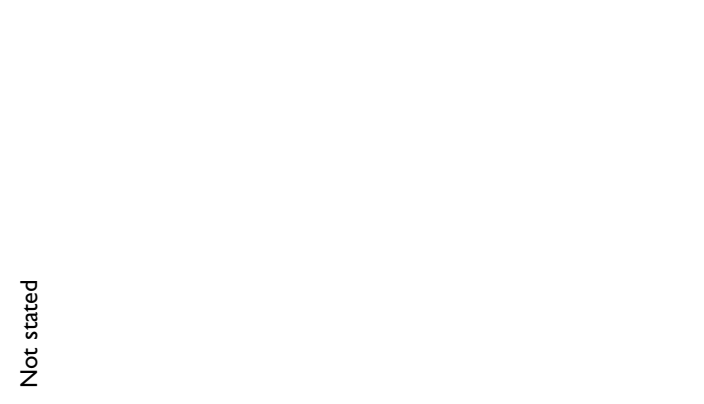 \\
\hline 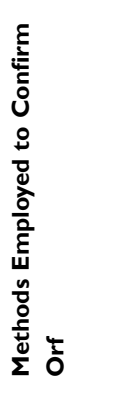 & 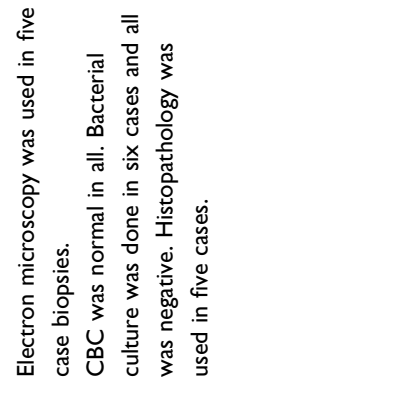 & 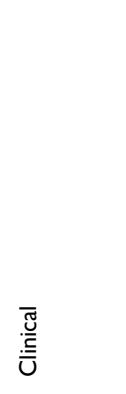 & 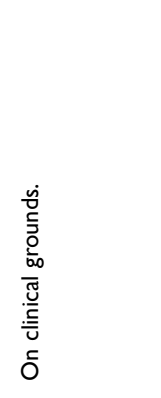 & 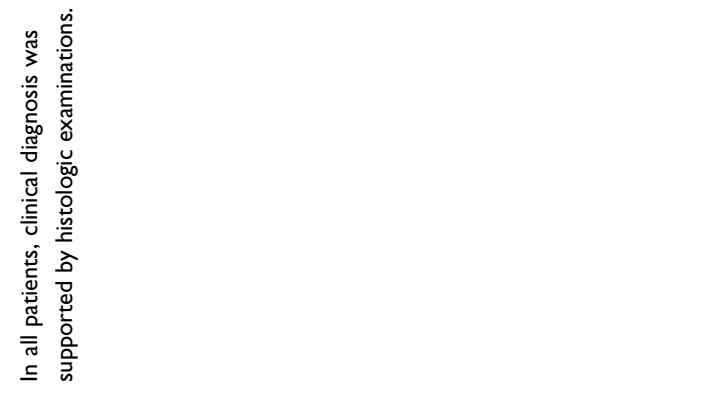 \\
\hline 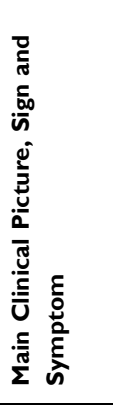 & 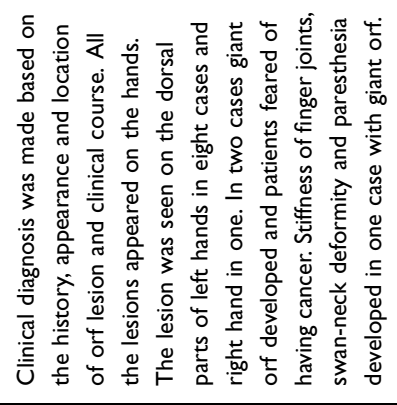 & 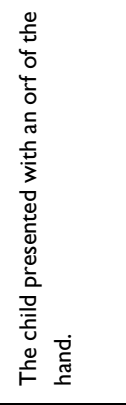 & 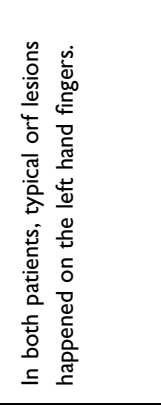 & 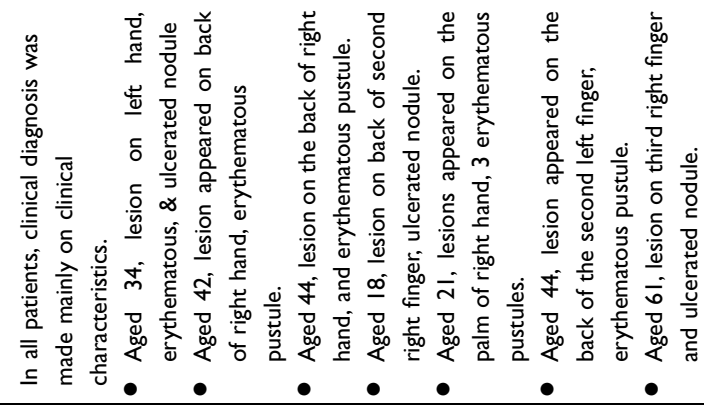 \\
\hline 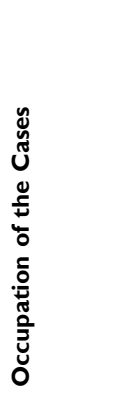 & 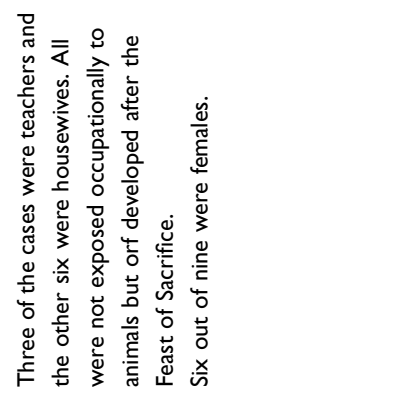 & 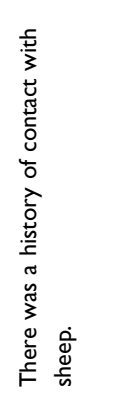 & 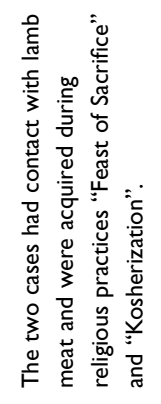 & 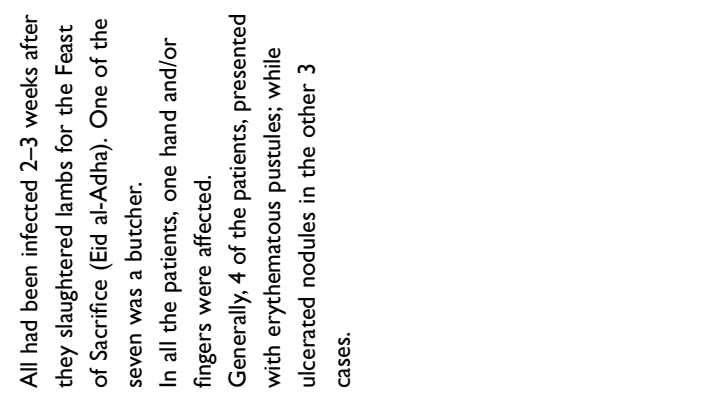 \\
\hline 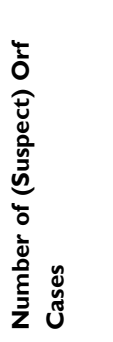 & 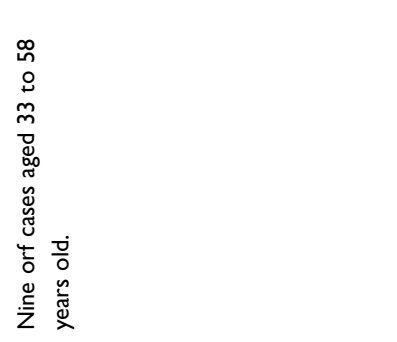 & 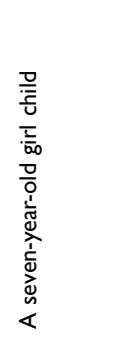 & 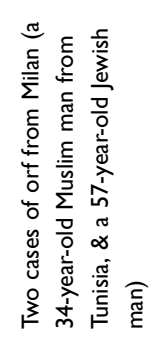 & 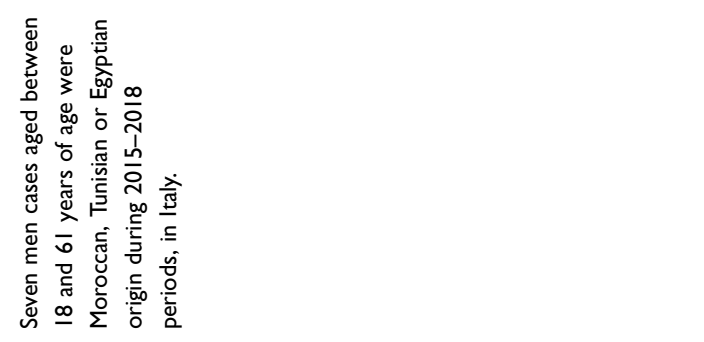 \\
\hline
\end{tabular}




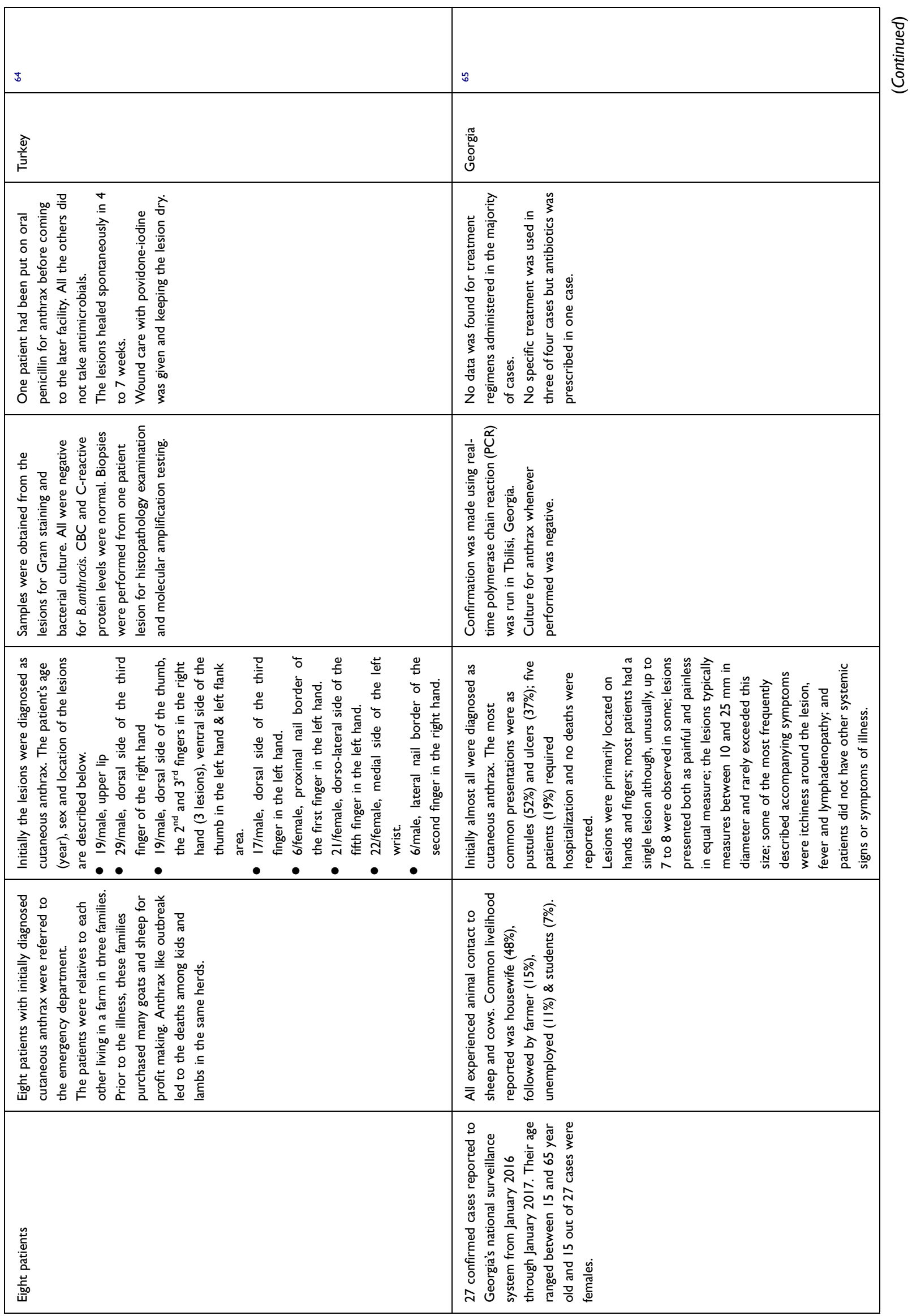




\begin{tabular}{|c|c|c|c|}
\hline 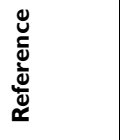 & ஃ & ธิ & $\stackrel{\infty}{\circ}$ \\
\hline 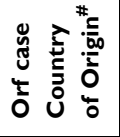 & 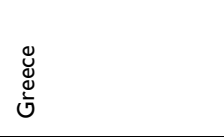 & 芯 & 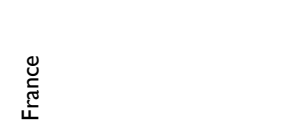 \\
\hline 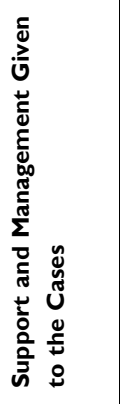 & 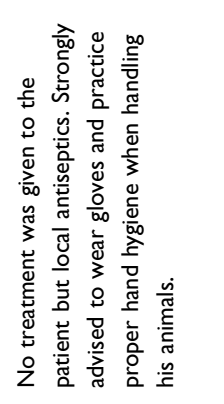 & 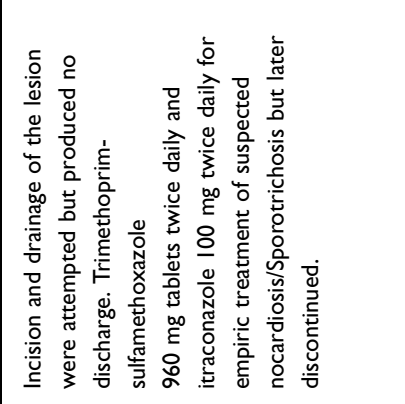 & 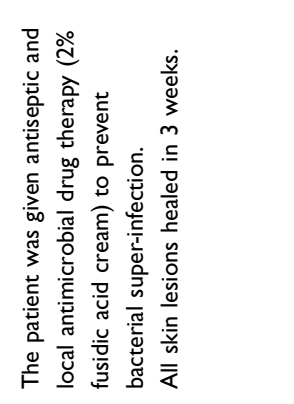 \\
\hline 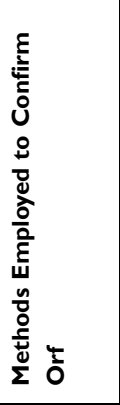 & 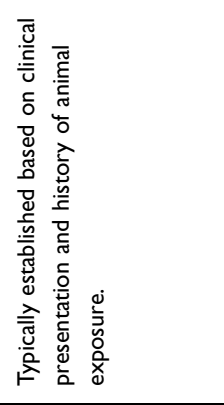 & 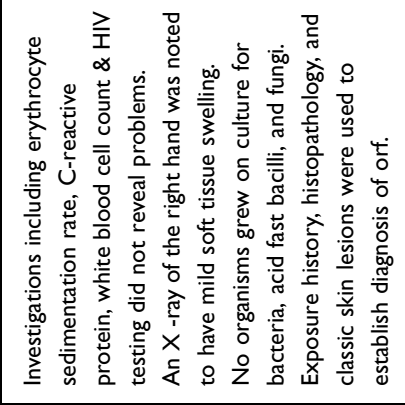 & 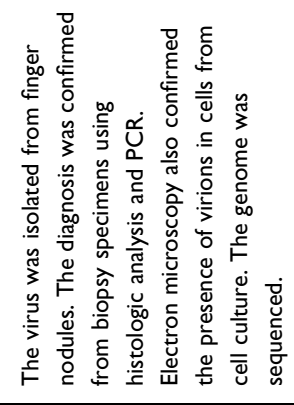 \\
\hline 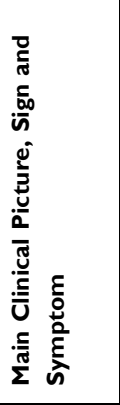 & 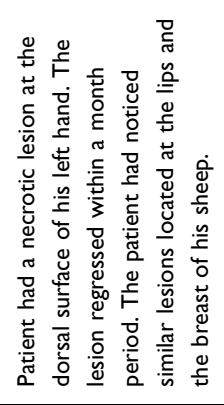 & 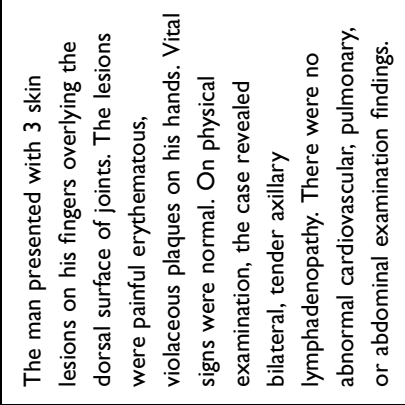 & 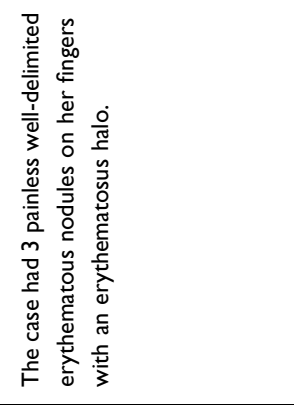 \\
\hline 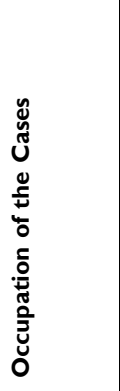 & 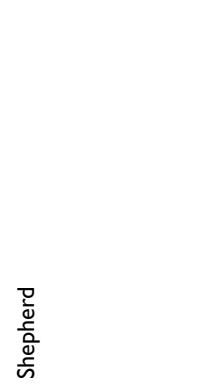 & 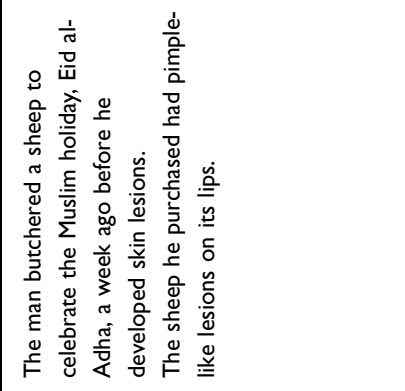 & 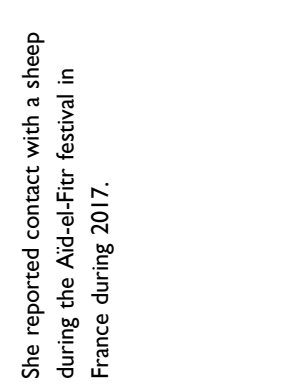 \\
\hline 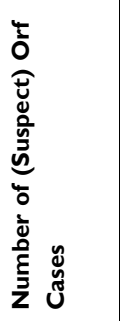 & 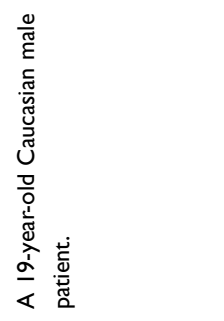 & 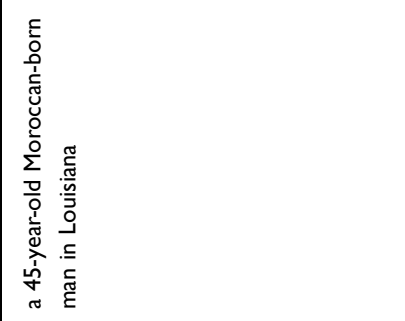 & 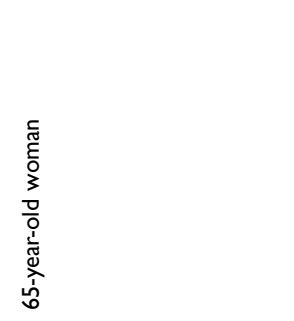 \\
\hline
\end{tabular}




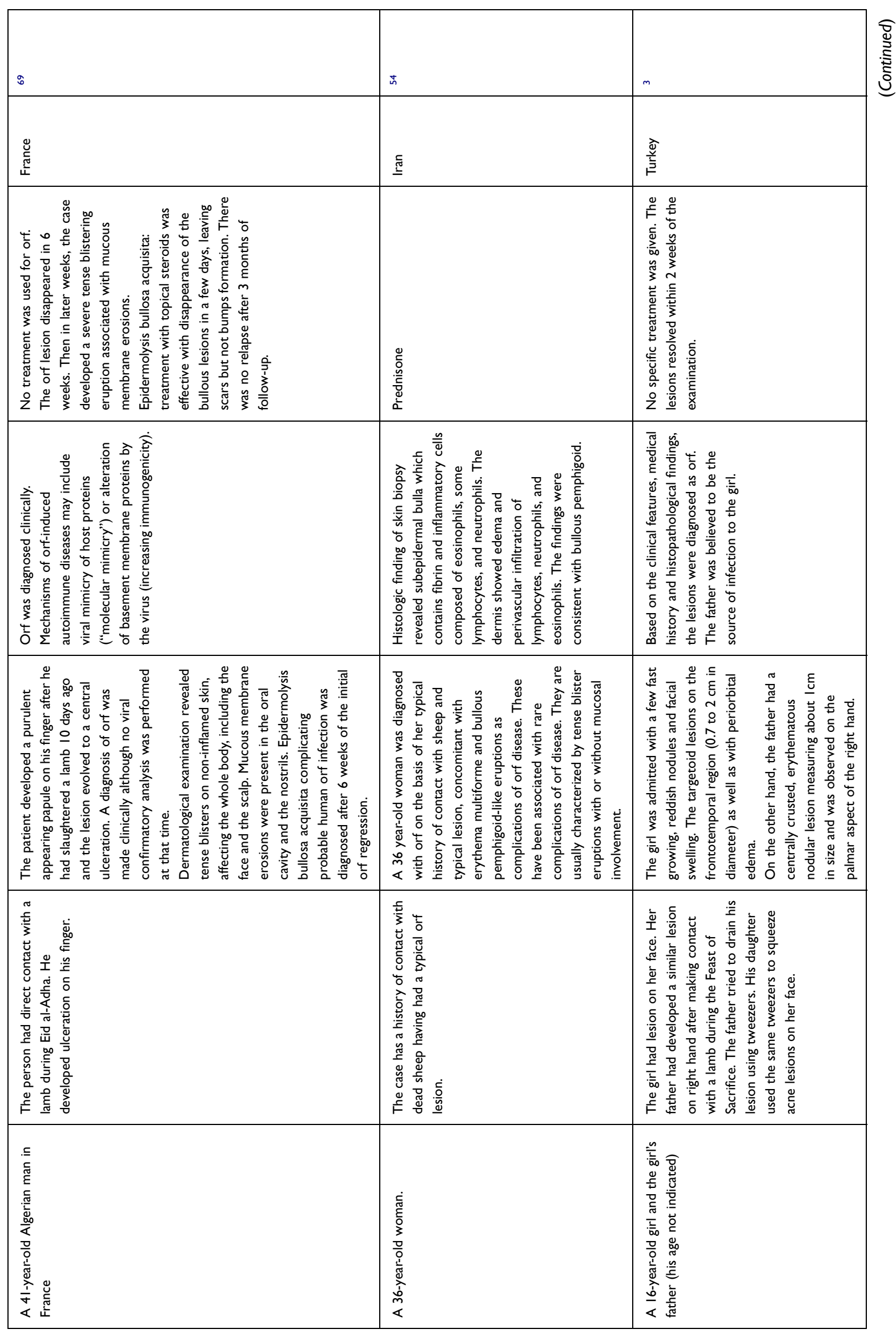




\begin{tabular}{|c|c|c|c|c|}
\hline 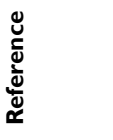 & 尺 & $\pi$ & f & $\approx$ \\
\hline 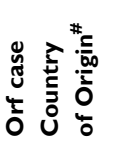 & 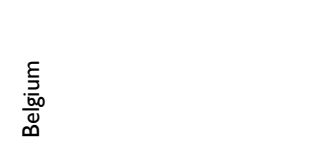 & 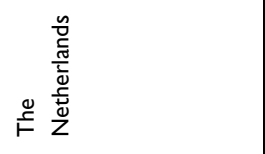 & 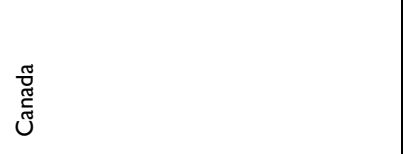 & 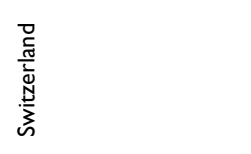 \\
\hline 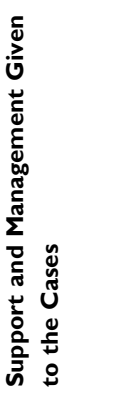 & 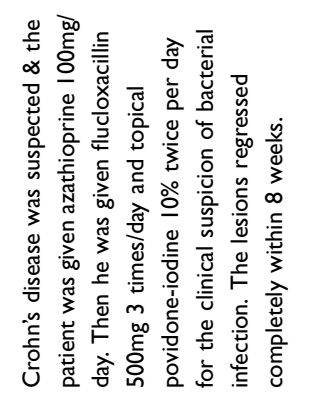 & 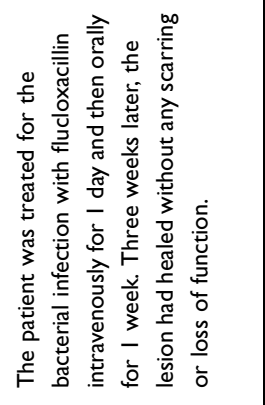 & 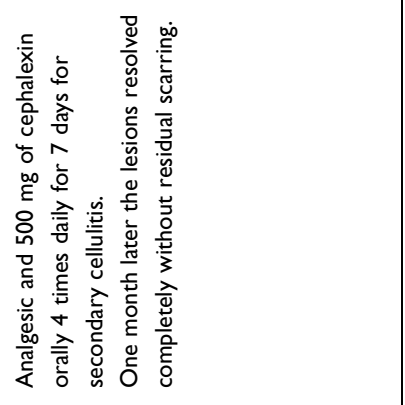 & 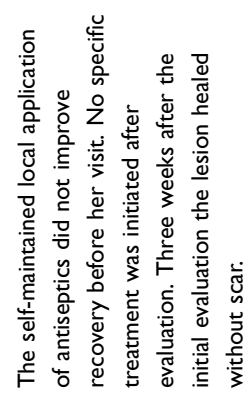 \\
\hline 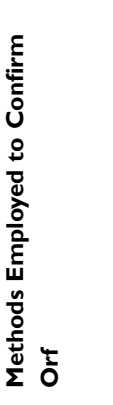 & 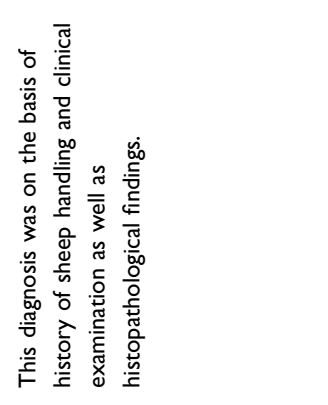 & 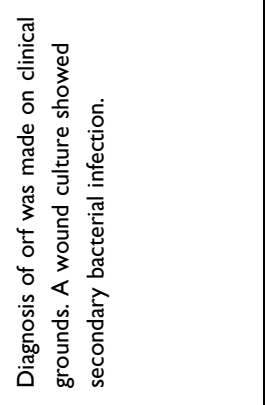 & 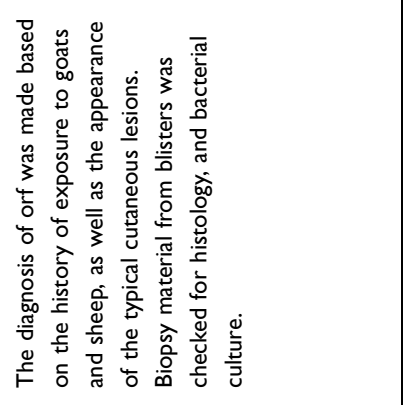 & 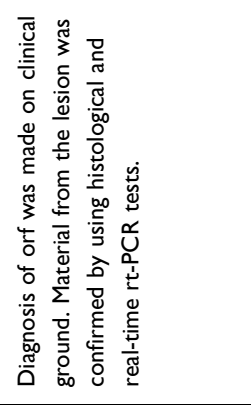 \\
\hline 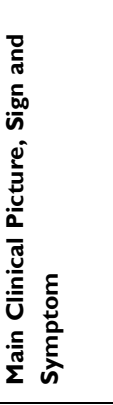 & 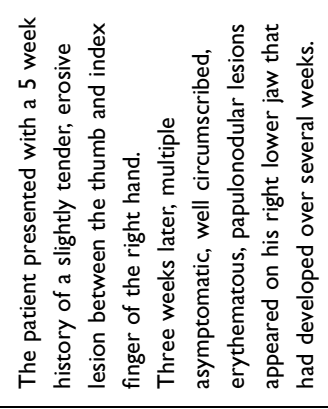 & 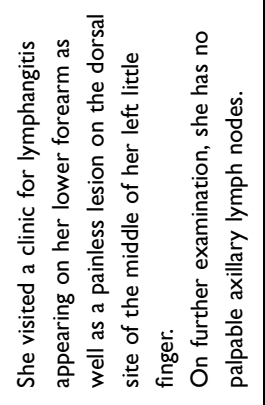 & 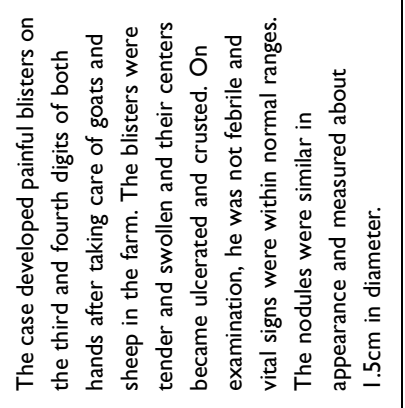 & 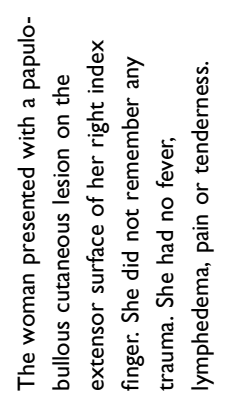 \\
\hline 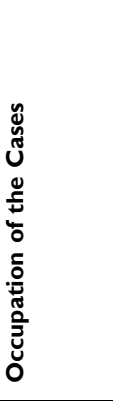 & 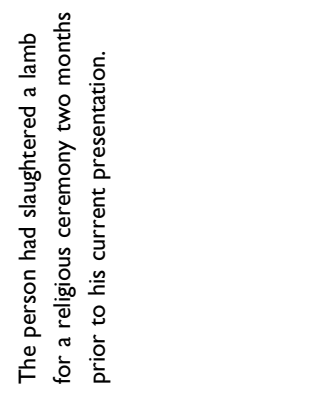 & 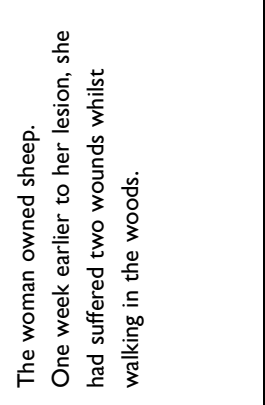 & 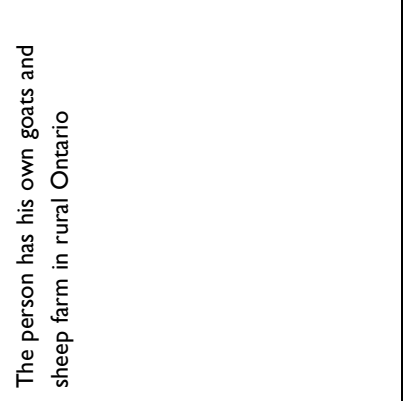 & 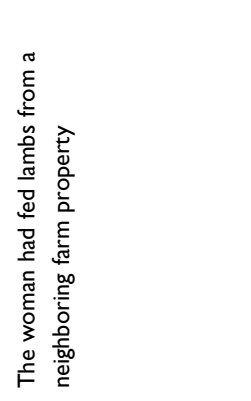 \\
\hline 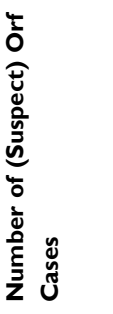 & 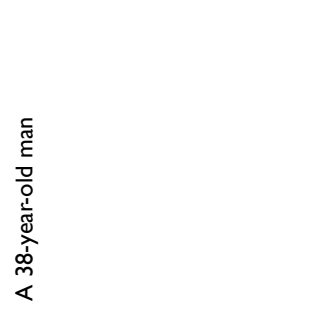 & 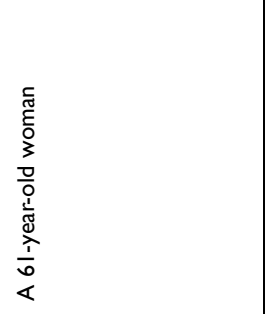 & 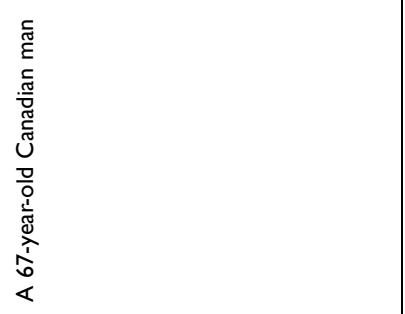 & 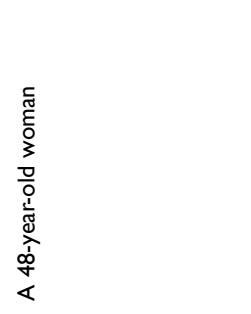 \\
\hline
\end{tabular}




\begin{tabular}{|c|c|c|}
\hline 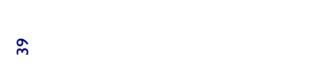 & $\approx$ & \pm \\
\hline 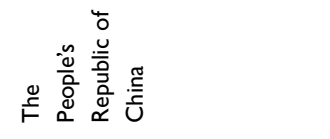 & 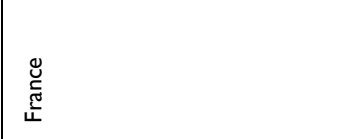 & 离 \\
\hline 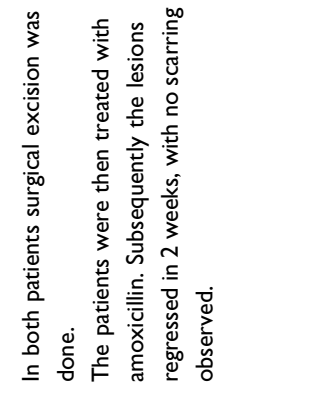 & $\frac{\mathbb{s}}{z}$ & 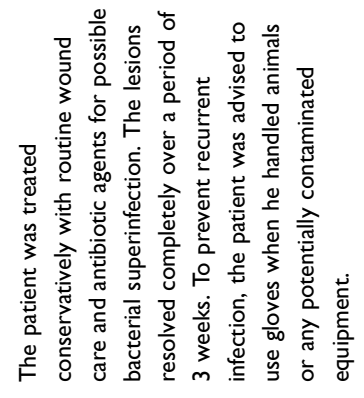 \\
\hline 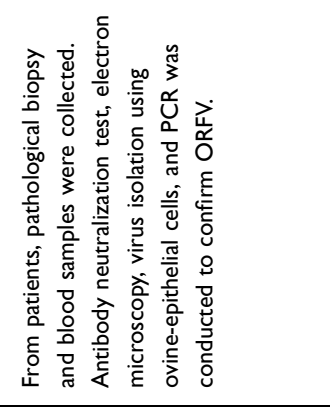 & 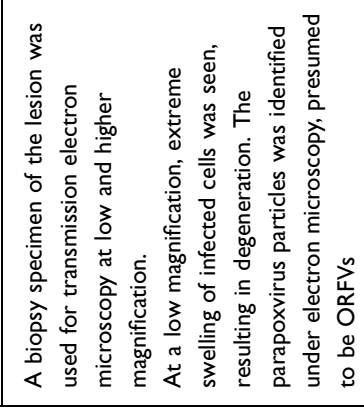 & 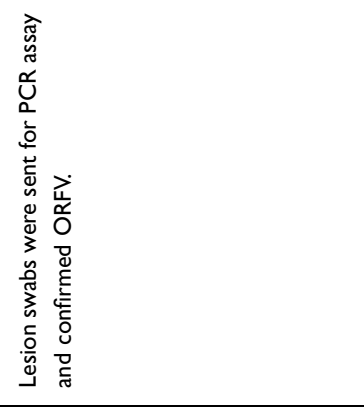 \\
\hline 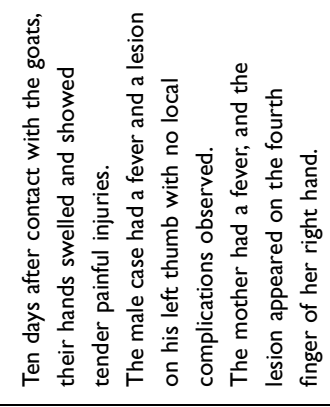 & 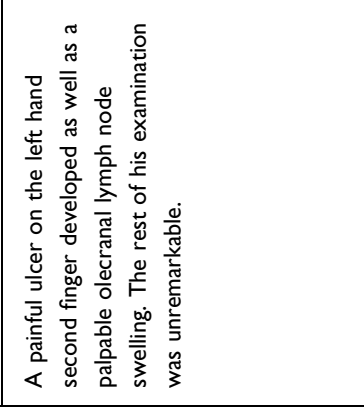 & 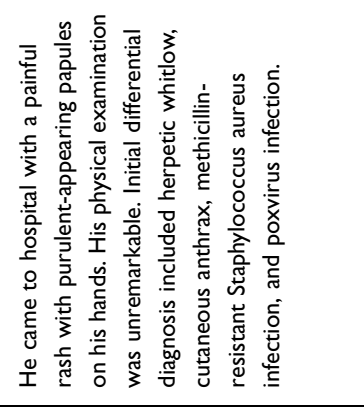 \\
\hline 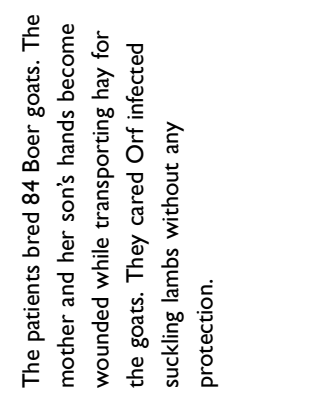 & 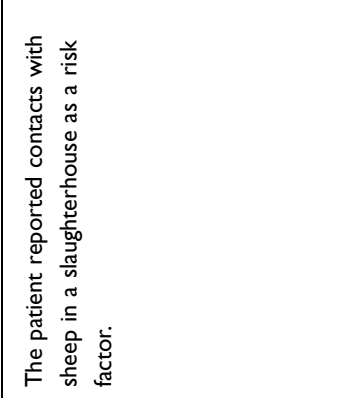 & 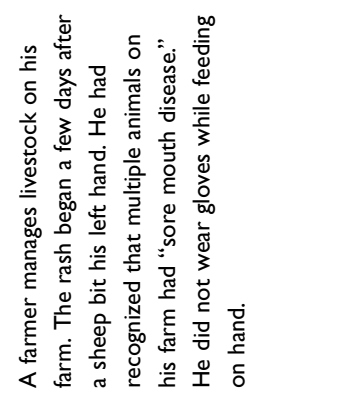 \\
\hline 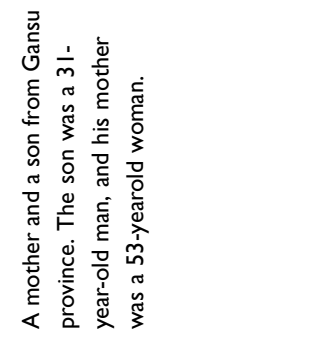 & 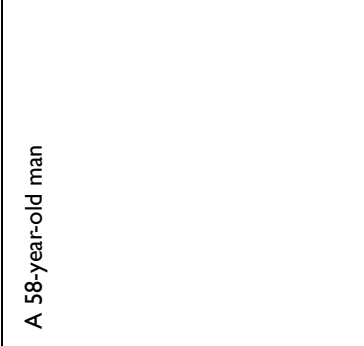 & 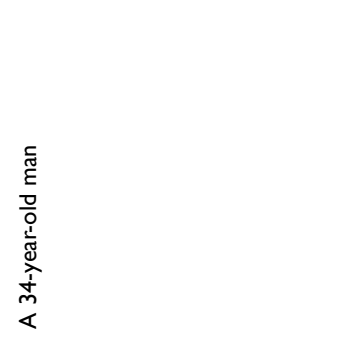 \\
\hline
\end{tabular}




\section{Laboratory Diagnosis}

Orf or EC are often diagnosed clinically on the grounds of history of exposure with animals together with the characteristic lesion on fingers, hands, forearms or face. ${ }^{46}$ However, various diagnostic tools are available to rule out ORFV from suspected cases, including virus cell culture system, transmission electron microscopy, direct immunofluorescent assay, various types of serological assays capable of detecting antigens or antibodies and genomic based molecular techniques such as PCR (conventional and real time method) and sequencing. ${ }^{16,78}$

Standard histopathology of a skin biopsy from suspected Orf may be of diagnostic value but still requires other laboratory methods to confirm the virus. Histologic findings show intraepidermal vesiculation (particularly in early lesion) when viewed under the microscope. Furthermore, epidermal hyperplasia with a scab or crust, variable epidermal vacuolation, eosinophilic inclusions in the nucleus or cytoplasm of keratinocytes, papillary dermal edema with diverse inflammatory lymphocytes, histiocytes, plasma cells and epidermal necrosis are also featured in later lesions. ${ }^{79}$ The epidermis typically displays noticeable pseudoepitheliomatous hyperplasia. Necrosis of the epidermis with ulceration in the epicenter of the lesion frequently arises. ORFV causes intranuclear and intracytoplasmic inclusion bodies with vacuolization and disaggregation of keratinocytes. Pyknosis of separate infected keratinocytes occurs in orf virus infection. ${ }^{80}$

The development of immunologic sera specific for parapoxviruses with the interest to pick ORFV is a simpler tool used for diagnostic purposes. However, serologic tests are not routinely implemented even if there is an obvious antibody response present for the virus. ${ }^{81}$ One of the drawbacks of this method is failure to discriminate ORFV from other species of parapoxvirus members like pseudocowpox virus. Therefore, such test results require confirmation with the use of other methods like specific antigen capture tests and electron microscopy with negative staining of material from suspect lesions.

Electron microscopy may be an unaffordable tool to make a routine diagnosis in settings like in Ethiopia and other developing countries where it is expensive to implement and requires highly skilled personnel to operate. In addition, the morphologic similarity of ORFV with the other Parapoxvirus members requires other specific tests for a definitive confirmation such as the ORFV specific antigen capture test. ${ }^{82}$ ORFV observed under electron microscopy demonstrates a classic ovoid crisscrossed viral particle that helps for differential diagnosis (Figure 1). ${ }^{27}$

On the other hand, ORFV isolation using different tissue culture systems and embryonated eggs are potential options; however, the growth rate of ORFV can be slow and variable. ${ }^{81}$ Moreover, isolation of the virus in tissue culture usually requires primary cell lines that are relatively difficult to obtain on a routine basis compared to continuous cell culture systems for the developing world.${ }^{83}$ The cell culture system is normally employed in a live attenuated ORFV vaccine preparation for animals such as primary neonatal bovine or ovine testicular cells used to culture the virus. ${ }^{81,83}$

Generally, the use of molecular methods is suitable for an effective diagnosis of Orf in humans. The various polymerase chain reaction tests are available from few laboratories around the world. ${ }^{1,16,17,78,84}$ Loop-mediated isothermal amplification (LAMP) assay has been developed that has a comparative sensitivity with PCR and nested PCR. According to Wang and his associates, LAMP and real-time PCR assays to detect ORFV from infected samples was compared and found that there was $97.8 \%$ agreement. Furthermore, the LAMP assay demonstrated a sensitivity of about $89.1 \%$. On the basis of this finding, LAMP assay has applicability in resource-limited settings as the test utilizes very minimal resources, stable reagents at tropical temperatures and faster than PCR turnaround times. ${ }^{86}$ The expansion and leverage of molecular techniques with the use of nucleic acid amplification methods including real time PCR and conventional PCR in many sub-Saharan African countries are becoming tangible because of global health program support for other etiologies including HIV, tuberculosis and currently COVID-19 or Severe Acute Respiratory Syndrome CoronaVirus-2. For this reason, the prepared set up is a worthy opportunity that can be easily transcribed at selected health facilities of a particular country and utilized for the diagnosis of other neglected viral etiologies of public health significance including ORFV.

\section{Treatment of ORF}

Orf or EC is generally assumed to be self-limiting among immunocompetent humans with no scarring after about 8 weeks and there is no specific choice of therapy. ${ }^{80}$ In most cases, the prognosis of Orf is excellent. Supportive therapy typically consists of local antiseptics and dressings are applied to minimize secondary bacterial infections as 
needed. Sometimes if the lesion appears on a finger, it may be important to immobilize the affected finger and antibiotics may be recommended to prevent bacterial infections.

Orf has been reported resolving with only supportive care in burn patients. ${ }^{45}$ Cryotherapy using liquid nitrogen facilitates recovery from Orf. ${ }^{87}$ Mortality from Orf has not been reported in humans. ${ }^{7}$

For diagnostic as well as therapeutic purposes, shave excision technique may be employed to remove portions of Orf lesions. For large, out-growing lesions, surgical dissection from the underlying dermis has been described. ${ }^{88}$ If the lesion is persistent and refractory, curettage and electro-desiccation can be employed as curative operations. ${ }^{7}$ In severe Orf cases on the fingers, amputation may be performed. However, it is only advised as a last chance remedy. ${ }^{43}$ In certain instances, the lesion is outsized with ulceration and necrosis that may become refractory to treatments and require amputation. ${ }^{48,89}$ Recurrences and delayed healing have been reported after surgical treatment. ${ }^{90}$ Generally, surgical procedures are usually reserved for immunocompromised patients who do not have the capacity to respond to more conservative measures. ${ }^{91}$

As ORFV is a DNA virus, it has a DNA dependent RNA polymerase. This enzyme serves as a target of antiviral drugs such as cidofovir. Cidofovir is a nucleotide analog that selectively inhibits viral DNA production in cytomegalovirus and other herpes viruses. The drug has been found almost ubiquitously used as a first-line antiviral therapy, along with mechanical excision of the Orf lesion. ${ }^{51}$ Cidofovir in cream and intravenous preparations were used in severe Orf cases, even though it is not approved for this use. ${ }^{80}$ The apparently successful use of cidofovir to treat a giant non-resolving ORFV infected lesion has been reported in an immunocompromised patient. ${ }^{48,92}$ The use of topical cidofovir cream has also been described due to its apparent benefit, despite the lack of controlled clinical trials to support this. ${ }^{93}$

Other reports described that Orf has been successfully treated with topical imiquimod application ${ }^{80,88}$ including in immunocompromised cases with very large Orf lesions. ${ }^{93}$ However, imiquimod, which is an immune response modifier, is not approved for treating ORFV infections. The product may induce secretions of interferon alpha and other cytokines where the mechanisms of action are not well elucidated. ${ }^{94}$ Generally, topical cidofovir or imiquimod have been particularly employed in patients with nonhealing or proliferative lesions, and immunocompromised. ${ }^{87}$ Interferon alpha-2a is another immune response modifier used rarely in Orf cases. It has antiviral, antiproliferative, and antiangiogenic properties and by so doing, it may stimulate the immune defense mechanism. ${ }^{48,95}$

\section{Epidemiology}

Orf or EC is particularly distributed in all sheep and goat raising countries worldwide. ${ }^{18,35}$ The virus further affects a wide range of animals including dogs, cats, horses, camels and other wild animals. ${ }^{15,75}$ The wide host ranges help the virus remain endemic in areas where the animals are prevalent, implying an opportunity for the virus and host interaction dynamicity remain predominant. $^{34}$ It affects all ages of animals but easily manifest in small aged ruminants and results in high fatality. ${ }^{7} \mathrm{ORFV}$ infection in kids of goats and lambs can lead to severe outcomes as it interferes with their feeding desire and they become debilitated. Moreover, secondary microbial infections due to bacteria and/or fungi through the damaged skin or mucous membranes become a reason for more than $90 \%$ mortality among one week aged lambs and kids. ${ }^{31}$

The epidemiology of ORFV among sheep, goats and other ruminant animals has been characterized in most parts of Africa including in Ethiopia. ${ }^{17,18,96,97}$ However, the incidence of human ORFV infection remains unreported or unknown in Ethiopia. This is probably because the majority of Orf cases do not seek medical attention or are misdiagnosed.

Orf in humans was chiefly described in the $20^{\text {th }}$ century:1934 by Newson and Cross. ${ }^{5}$ ORFV is known to infect all age groups in humans but the incidence is commonly seen among adults with a history of exposure to animals. Those people involved in animal businesses such as farm workers, abattoir workers, veterinarians, students in animal science, petting zoos and others working with animals are at increased risk of acquiring the virus. ${ }^{9,98}$

There is no racial preference reported for Orf although the disease is more commonly reported among men. This is owing to the fact that men are more likely to have occupational exposure while serving as sheep breeders, goat or sheep dealers, slaughter workers, etc. ${ }^{90}$ As most Orf cases have been attributed to religious observances such as sacrificial feasts, ${ }^{56}$ there was a widespread custom of slaughtering small ruminates in backyards during Eid al-Adha. ${ }^{1,18,43,63,99-101}$ The virus is known to survive in different conditions for weeks to months and even to years 
as described above in the Transmission and Pathogenesis section. It was also demonstrated that some chronically infected animals are known to carry the virus without visible lesions. ${ }^{1,35}$ In humans, ORFV re-infection was noted $^{57}$ and infected individuals must be advised to minimize auto-inoculation, spread of infection to contacts including animals or should not handle animals without protective precautions. ${ }^{80}$

Until recently, only the clinical symptoms and history of animal contacts were used in the suspicion of human orf lesions unlike in animals where a sign of ORFV infection on skin and mucous membrane is important in Jimma town, Ethiopia. Suspect human cases with a minimum age of 9 years have been found among visiting patients at Jimma University medical center originating from the town. There were no confirmatory laboratory tests available at the facility to identify ORFV or perform specific molecular characterization assays from biopsied materials. ${ }^{14}$

Orf or EC appears to be neglected among animals owing to its minimal impact on the animal production and economic loss. ${ }^{102}$ Different studies have shown the phylogenetic relatedness of ORFV isolates from diverse animal sources. ${ }^{103,104}$ The findings help to predict and assess the extent of the risk to human health. While considerable information on animal and human Orf is available from other regions of the world, such as in Europe, Asia and the USA, only very few studies on animals have been conducted in Africa. ${ }^{105}$ So far, some molecular studies on ORFV infections among small ruminants have been reported from Ethiopia, Gabon, South Africa, and Egypt. ${ }^{5,14,99,106,107}$ The disease has also been reported infecting camels in Africa. ${ }^{56}$ Several others also confirmed ORFV infections from sheep, goats and camel in different African countries including Kenya, Somalia, Sudan, Tanzania, Cameroon, Nigeria and Zambia. ${ }^{5,18,97,107-109}$ There are some additional published reports that orf disease in animals was diagnosed on the basis of clinical findings. ${ }^{12,63,82,99,110}$

In recent times, the increasing trend of Orf infections is noticeable due to the emergence of the virus in new geographic locations. This may be associated with the expansion in interspecies infection as well as the possibility of reinfection in previously infected animals. ${ }^{5,18}$ Different studies showed a high incidence rate (ranging from 75$90 \%$ ) of Orf among animal herds throughout the dry season in parts of the central African region. The actual prevalence may be significantly underestimated among livestock herds as well as humans ${ }^{4,96}$ that may be because many people who had contact with animals recognize Orf lesions and they did not seek medical attention. A series of Orf suspected human cases were attended in Jimma town between the months of October 2019 and May 2020. This period encompasses the drier seasons in most parts of Ethiopia.

\section{Prevention and Control}

Since animals are essentially reservoirs and sources of ORFV infection in humans, the principal preventive measure must be to target animals for vaccination. ${ }^{111}$ There are live attenuated ORFV vaccine candidates for sheep and goats. ${ }^{34}$ Care must be taken while handling this vaccine product or from vaccinated animals as the virus can pose an infection risk to humans. ${ }^{4}$ There are reports of the vaccine used for ORFV resulting in human infection. ${ }^{112,113}$ It is recommended that infected or vaccinated animals should be put in isolation away from human and healthy animals to prevent contact, potentially leading to transmission. Wearing non-permeable gloves or regular hand washing practice with warm soapy water or by using hand sanitizer for 20 seconds after handling sheep or goats is recommended to minimize the risk of human infections. ${ }^{1}$

Patients who are particularly immunosuppressed must avoid contact with animals as they have an increased susceptibility to potentially severe ORFV infection. To aid in preventing transmission to humans, any visible (or invisible) cuts or abrasions on the skin should be covered to avoid contact exposure to animal scabs or animal products like meat, wool or hides, the use of non-porous gloves is recommended for this purpose. ${ }^{7}$

It is important to provide health information about the virus routes of transmission and its disease manifestations to farmers and people who handle animals or animal products. People should also be informed of the potential recurrences of infection due to repeated exposure to the virus. ${ }^{1}$ In endemic locations, confirmation of the presence of the virus from human or animal lesions, surveillance implementations, and infection control measurements are important to employ by integrating the public health interface of both human and animal sectors.

\section{Conclusion}

Orf, ecthyma contagiosum or contagious ecthyma is an exanthematic debilitating disease of sheep and goats with zoonotic potential to affect humans but is largely a neglected disease in developing countries. It is caused by 
ORFV, a member of the Parapoxvirus genus in poxviuses. Orf has increasing incidences that have been reported worldwide, which extends to Africa albeit from a limited amount of information. Orf is known to occur in rural as well as urban areas due to lack of awareness, casual negligence through religious or cultural practices involving animal handling and slaughter. Though the disease is self-limiting in a majority of human cases in Jimma town, the significant count of small ruminants coming from diverse areas are considered highly likely to have contributed to the emergence of ORFV in Jimma town in Ethiopia. Differential diagnosis, and prompt treatment of affected humans as well as the use of a vaccine in animals could help prevent the spread of the virus. Human to human transmission exists, though only under very rare conditions, making improved control in animal sources the most effective way of reducing the incidence of this disease in humans.

The constant presence of the virus in the environment increases the risk of ORFV exposure among humans as well as interspecies transmission between animals. Furthermore, ORFV does not generate enduring immunity in humans. Health professionals in most parts of Ethiopia, as well as in other similar settings across Africa, may not be familiar with infections by this virus. This knowledge gap leads to overtreatment or other medical errors. Whereas Orf or EC diagnosis is mostly based on clinical findings as well as a history of animal contact, its resemblance to other skin manifestations requires differential confirmed diagnosis from potentially life-threatening zoonotic infections. This includes the use of molecular tests that also help to track the epidemiology of the virus. As there is no specific treatment in human Orf except in immunocompromised cases, surveillance implementations and infection control measurements are very important to stop ORFV circulation.

\section{Acknowledgments}

I thank Dr. Adane Mihret, senior scientist at Armer Hansen Research Institute and faculty member at Addis Ababa University, Addis Ababa, Ethiopia, for important discussions we made on the title frame and for the English editing. I thank Jimma University library for availing some of the subscribed journals. I am thankful to the orf case patient for their willingness to give consent for publication of the photograph in Figure 1.

\section{Disclosure}

The author reported no conflicts of interest for this work and has no affiliations or financial involvement with any organization or entity with a financial interest or financial conflict with the scientific area discussed in this review. There is no finance received to write this manuscript in any form. No writing assistance was utilized in the development of this review.

\section{References}

1. CDC. Infection in People | orf Virus (Sore Mouth Infection) | poxvirus CDC. 2019. Available from: https://www.cdc.gov/pox virus/orfvirus/people.html Accessed September 5, 2020.

2. Knipe DM, Howley PM, editors.Fields Virology. 5th ed. Lippincott Williams \& Wilkins;2006.

3. Turk BG, Senturk B, Dereli T, Yaman B. A rare human-to-human transmission of orf. Int $J$ Dermatol. 2014;53(1):e63-e65. doi:10.1111/j.13654632.2012.05669.x

4. Kumar R, Trivedi RN, Bhatt $\mathrm{P}$, et al. Contagious Pustular Dermatitis (Orf Disease) - Epidemiology, diagnosis, control and public health concerns. Adv Anim Vet Sci. 2015;3(12):649-676. doi:10.14737/journal.aavs/2015/3.12.649.676

5. Maganga GD, Relmy A, Bakkali-Kassimi L, et al. Molecular characterization of Orf virus in goats in Gabon, Central Africa. Virol J. 2016;13(1):79. doi:10.1186/s12985-016-0535-1

6. Hajkazemi MB, Bokaie S, Mirzaie K. A review of contagious ecthyma (orf) in sheep and goats and the status of disease in Iran. Review. 2016;5(9).

7. Spickler AR Contagious Ecthyma. 2015. http://www.cfsph.ias tate.edu/DiseaseInfo/factsheets.php

8. Central Statistical Agency of Ethiopia. Agricultural sample survey agricultural sample survey 2018/19 [2018/19 [2011e.c.] volume II report on livestock and livestock characteristics (private peasant holdings). 2019.

9. Paiba GA, Thomas DR, Morgan KL, Bennett M, Salmon RL. Orf (contagious pustular dermatitis) in farmworkers: prevalence and risk factors in three areas of England - ProQuest. Vet Rec. 1999;145:1. doi:DOI:10.1136/vr.145.1.7

10. Adedeji AJ, Adole JA, Chima NC, et al. Contagious ecthyma in three flocks of goats in Jos-south LGA, Plateau State, Nigeria. Sokoto Journal of Veterinary Sciences. 2018;16(1):107. doi:10.4314/sokjvs.v16i1.16

11. Gardiner MR, Craig J, Nairn ME. An unusual outbreak of contagious ecthyma (scabby mouth) in sheep. Australian Vet J. 1967;43(5):163-165. doi:10.1111/j.17510813.1967.tb04827.x

12. Ferede Y, Habtamu A, Gebresellasie S. Confirmatory diagnosis of contagious ecthyma (Orf) by polymerase chain reaction at Adet Sheep Research Sub-Center, Ethiopia: a case report. J Vet Med Anim Hlth. 2014;6(7):5.

13. Woldemeskel M, Ashenafi H. Study on skin diseases in sheep from northern Ethiopia. DTW Dtsch Tierarztl Wochenschr. 2003;110(1):20-22.

14. Gelaye E. Genetic characterization of poxviruses in Camelus dromedarius in Ethiopia, 2011-2014. Antiviral Res. 2016;9.

15. Tedla M Molecular identification and investigations of contagious ecthyma (Orf virus) in small ruminants, North west Ethiopia. 2018:8.

16. Torfason EG, Guðnadóttir S. Polymerase chain reaction for laboratory diagnosis of orf virus infections. $J$ Clin Virol. 2002;24(1):79-84. doi:10.1016/S13866532(01)00232-3 
17. Kusiluka L, Kambarage D; VETAID, Great Britain, Animal Health Programme. Diseases of Small Ruminants: A Handbook : Common Diseases of Sheep and Goats in Sub-Saharan Africa. VETAID; 1996.

18. CABI. contagious ecthyma. November 25, 2019. Available from: https://www.cabi.org/isc/datasheet/88087\#tooverview Accessed October 1, 2020.

19. Etymologia: orf. Emerg Infect Dis. 2013;19(1):105. doi:10.3201/ eid1901.ET1901

20. CDC C. Poxvirus. CDC.2020. Available from: https://www.cdc. gov/poxvirus/index.html. Accessed October 13, 2020.

21. ICTV. International Committee on Taxonomy of Viruses. ICTV; 2019. Available from: https://talk.ictvonline.org/taxonomy/p/taxo nomyhistory?taxnode id $=201904780$. Accessed September 6, 2020.

22. Baxby D. Poxviruses. In: Baron S, editor. Medical Microbiology. 4th ed. University of Texas Medical Branch at Galveston; 1996. Available from: http://www.ncbi.nlm.nih.gov/books/NBK8364/. Accessed September 6, 2020.

23. Fleming SB, Wise LM, Mercer AA. Molecular genetic analysis of orf virus: a poxvirus that has adapted to skin. Viruses. 2015;7 (3):1505-1539. doi:doi:10.3390/v7031505

24. Delhon G, Tulman ER, Afonso CL, et al. Genomes of the Parapoxviruses Orf virus and bovine papular stomatitis virus. JVI. 2004;78(1):168-177. doi:10.1128/JVI.78.1.168177.2004

25. Likos A, Goldsmith C. Details; Public Health Image Library (PHIL). United States Centers for Disease Control and Prevention; 2020. Available from: https://phil.cdc.gov/Details. aspx?pid=8434. Accessed November 29, 2020.

26. Spehner D, Carlo SD, Drillien R, et al. Appearance of the bona fide spiral tubule of orf virus is dependent on an intact 10-kilodalton viral protein. $J$ Virol. 2004;78(15):8085-8093. doi:10.1128/JVI.78.15.8085-8093.2004

27. Nashiruddullah N, Pathak DC, Barman NN, et al. In vitro and in vivo assessment of orf virus (ORFV) by electron microscopy. Veterinarski Arhiv. 2018;88(6):847-861. doi:10.24099/vet. arhiv.0229

28. Groves RW, Wilson-Jones E, MacDonald DM. Human orf and milkers' nodule: a clinicopathologic study. J Am Acad Dermatol. 1991;25(4):706-711. doi:10.1016/0190-9622(91)70257-3

29. Mercer A, Fleming S, Robinson A, Nettleton P, Reid H. Molecular genetic analyses of parapoxviruses pathogenic for humans. In: Kaaden O-R, Czerny C-P, Eichhorn W editors. Viral Zoonoses and Food of Animal Origin. Springer; 1997:2534. doi:10.1007/978-37091-6534-8_3.

30. Mercer A, Ueda N, Friederichs S-M, et al. Comparative analysis of genome sequences of three isolates of Orf virus reveals unexpected sequence variation. Virus Res. 2006;116(12):146-158. doi:10.1016/j.virusres.2005.09.011

31. Zhang K, Liu Y, Shang Y, Liu X, Cai X. Major virulence factors of orf virus and their mechanism for immune evasion. Austin $J$ Infect Dis. 2014;(1):1. https://austinpublishinggroup.com/infec tious-diseases/fulltext/ajid-v1-id1005.php. Accessed, 2020.

32. Wang R, Luo S. Orf virus: a new class of immunotherapy drugs. In: Systems Biology. IntechOpen;2018: 17. Available from: https://www.intechopen.com/books/systems-biology/orf-virus-anew-class-ofimmunotherapy-drugs. Accessed September 29, 2020

33. McInnes CJ, Wood AR, Mercer AA. Orf Virus Encodes a Homolog of the Vaccinia Virus Interferon-Resistance Gene E3L | springerLink. Virus Genes. 1998;17:9. doi:10.1023/A:1026431704679

34. Hosamani M, Scagliarini A, Bhanuprakash V, McInnes CJ, Singh RK. Orf: an update on current research and future perspectives. Expert Rev Anti Infect Ther. 2009;7(7):879-893. doi:10.1586/ eri.09.64
35. Fleming SB, Mercer AA. Genus Parapoxvirus. In: Mercer AA, Schmidt A, Weber O editors. Poxviruses. Birkhäuser Basel; 2007:127-165. doi:10.1007/978-3-7643-7557-7_7.

36. Lyttle DJ, Fraser KM, Fleming SB, Mercer AA, Robinson AJ. Homologs of vascular endothelial growth factor are encoded by the poxvirus orf virus. J Virol. 1994;68(1):84-92.

37. Savory LJ, Stacker SA, Fleming SB, Niven BE, Mercer AA. Viral vascular endothelial growth factor plays a critical role in orf virus infection. J Virol. 2000;74(22):10699-10706.

38. Fleming SB, McCaughan C, Lateef $Z$, et al.. Deletion of the chemokine binding protein gene from the parapoxvirus orf virus reduces virulence and pathogenesis in sheep. Front Microbiol. 2017;8. doi:doi:10.3389/fmicb.2017.00046

39. Zhang K, Liu Y, Kong H, Shang Y, Liu X. Human Infection with Orf Virus from Goats in China, 2012. Vector Borne Zoonotic Dis. 2014;1(1):3. doi:10.1089/vbz.2013.1445

40. Diel DG, Delhon G, Luo S, Flores EF, Rock DL, Novel A. Inhibitor of the NF- $\mathrm{KB}$ signaling pathway encoded by the parapoxvirus orf virus. J Virol. 2010;84(8):3962-3973. doi:10.1128/ JVI.02291-09

41. Deane D, McInnes CJ, Percival A, et al. Orf virus encodes a novel secreted protein inhibitor of granulocyte-macrophage colony-stimulating factor and Interleukin-2. J Virol. 2000;74(3):1313-1320. doi:10.1128/JVI.74.3.1313-1320.2000

42. Monath TP. Vaccines against diseases transmitted from animals to humans: a one health paradigm. Vaccine. 2013;31(46):53215338. doi:10.1016/j.vaccine.2013.09.029

43. Uzel M, Sasmaz S, Bakaris S, et al. A viral infection of the hand commonly seen after the feast of sacrifice: human orf (orf of the hand). Epidemiol Infect. 2005;133(4):653-657. doi:10.1017/ s0950268805003778

44. Rajkomar V, Hannah M, Coulson IH, Owen CM. A case of human to human transmission of orf between mother and child. Clin Exp Dermatol. 2016;41(1):6063. doi:10.1111/ced.12697

45. Midilli K, Erkılıç A, Kuşkucu M, et al. Nosocomial outbreak of disseminated orf infection in a burn unit, Gaziantep, Turkey, October to December 2012. Eurosurveillance. 2013;18:11. doi:10.2807/ese.18.11.20425-en

46. Ginzburg VE, Liauchonak I. Human orf. Can Fam Physician. 2017;63(10):769-771. Available from: https://www.ncbi.nlm.nih. gov/pmc/articles/PMC5638474/. Accessed, 2020.

47. Teshale A. Contagious Ecthyma and its Public Health Significance. JDVS. 2018;7:3. doi:10.19080/JDVS.2018.07.555711

48. Lederman ER, Green GM, DeGroot HE, et al. Progressive orf virus infection in a patient with lymphoma: successful treatment using imiquimod. Clin Infect Dis. 2007;44(11):e100-e103. doi: $10.1086 / 517509$

49. Ata N, Gögüs HE, Giant KS. Orf on the Nose. J Craniofacial Surg. 2017;28(3):e234. doi:10.1097/SCS.0000000000003441

50. Geerinck K, Lukito G, Snoeck R, et al. A case of human Orf in an immunocompromised patient treated successfully with cidofovir cream. J Med Virol. 2001;64(4):543-549. doi:10.1002/jmv.1084

51. Faridi W, Ahmed K. Orf Disease. In: StatPearls. StatPearls Publishing. Available from: http://www.ncbi.nlm.nih.gov/books/ NBK562191/. 2020. Accessed September 30, 2020.

52. Taghipour M, Babamahmoodi F, Arashnia P, Taghipour S. Orf Virus Infection in Human (EchtymaContagiosum): a report of eight cases in the North of Iran. Int J Med Invest. 2015;4(1):4.

53. Mourtada I, Le Tourneur M, Chevrant-Breton J, Le Gall F. [Human orf and erythema multiforme]. Ann Dermatol Venereol. 2000;127(4):397-399.

54.. Alian S, Ahangarkani F, Arabsheybani SA. Case of orf disease complicated with erythema multiforme and bullous pemphigoidlike eruptions. Case Rep Infect Dis. 2015;2015. doi:10.1155/ $2015 / 105484$. 
55. Joseph RH, Haddad FA, Matthews AL, Maroufi A, Monroe B, Reynolds M. Erythema multiforme after orf virus infection: a report of two cases and literature review. Epidemiol Infect. 2015;143(2):385-390. doi:10.1017/S0950268814000879

56. Al-Qattan MM. Orf Infection of the Hand. $J$ Hand Surg Am. 2011;36(11):1855-1858. doi:10.1016/j.jhsa.2011.08.019

57. Cubells JRE, Braverman I, Kashgarian M, Lazova R. A 65-yearold female from connecticut with orf infection. Dermatopathology (Basel). 2016;3(2):55-60. doi:10.1159/000447125

58. Orf virus infection of workers in the meat industry. $N Z$ Med J. 1983;96(725):81-85.

59. Sasmaz S, Uzel M, Ucmak H Rare presentation of human orf as multiple lesions. 2010. Available from: https://login.research4life. org/tacsgr1onlinelibrary_wiley_com/doi/full/10.1111/j.13468138. 2010.01082.x. Accessed January 6, 2021.

60. Erbağci Z, Erbağci İ, Tuncel AA. Rapid improvement of human orf (ecthyma contagiosum) with topical imiquimod cream: report of four complicated cases. J Dermatol Treat. 2005;16(5-6):353356. doi:10.1080/09546630500375734

61. Waldram MA. A seven-year-old girl with orf of the hand. $J$ Hand Surg. 1986;11(3):467-468. doi:10.1016/0266-7681(86)90186-5

62. Veraldi S, Nazzaro G, Vaira F, Çuka E. Presentation of orf (ecthyma contagiosum) after sheep slaughtering for religious feasts. Infection. 2014;42(4):767-769. doi:10.1007/s15010-014-0591-7

63. Veraldi S, et al. Feast of Sacrifice and Orf, Milan, Italy, 2015-2018. Emerg Infect Dis. 2019;25(8):1585-1586. doi:10.3201/eid2508.181063

64. Bayindir Y, Bayraktar M, Karadag N, et al. Investigation and analysis of a human orf outbreak among people living on the same farm. New Microbiol. 2011;34:8.

65. Chakhunashvili G, Carlson BF, Power L, et al. Parapoxvirus infections in the country of Georgia: a case series. Am J Trop Med Hyg. 2018;98(6):1870-1875. doi:10.4269/ajtmh.17-0874

66. Koufakis T, Katsaitis P, Gabranis I. Orf disease: a report of a case. Braz J Infect Dis. 2014;18(5):568-569. doi:10.1016/j.bjid.2014.04.001

67. Vellucci A, Manolas M, Jin S, et al. Orf virus infection after Eid al-Adha. IDCases. 2020;21:e0854. doi:10.1016/j.idcr.2020 e00854

68. Andreani J, Fongue J, Khalil JYB, et al. Human Infection with Orf Virus and Description of Its Whole Genome, France, 2017 Volume 25, Number 12-December 2019 - Emerging Infectious Diseases journal - CDC. EID. 2019;25:12. doi:10.3201/ eid2512.181513

69. Zuelgaray E, Salle de Chou C, Gottlieb J, et al. Human orf complicated by epidermolysis bullosa acquisita. Br J Dermatol. 2018;178(2):547-550. doi:10.1111/bjd.15496

70. Duchateau NC, Aerts O, Lambert J. Autoinoculation with Orf virus (ecthyma contagiosum). Int J Dermatol. 2014;53(1):e60e62. doi:10.1111/j.1365-4632.2012.05622.x

71. Friebel TR, van der Werff JFA. The orf virus: a case report. $J$ Hand Surg. 2013. doi:10.1177/1753193413516403

72. Meier R, Sommacal A, Stahel A, Grünert J, Hoffmann M. Orf an orphan disease?. JRSM Open. 2015;6(6). doi:10.1177/ 2054270415593718

73.. Roingeard P, Machet L. Orf skin ulcer. N Engl J Med. 1997;337 (16): 1 .

74. Thurman RJ, Fitch RW, Contagious Ecthyma. $N$ Engl $J$ Med. 2015;372(8):1. doi:10.1056/NEJMicm1304779

75. Haig DM. Orf virus infection and host immunity. Curr Opin Infect Dis. 2006;19(2):127-131. doi:10.1097/01. qco.0000216622.75326.ef

76. Muhsen M, Protschka M, Schneider LE, Müller U, Köhler G, Magin T. Orf virus (ORFV) infection in a three-dimensional human skin model: characteristic cellular alterations and interference with keratinocyte differentiation. PLOS ONE. 2019;14(1):22. doi:10.1371/journal.pone.0210504
77. Sahu BP, Majee P, Singh RR, Sahoo A, Nayak D. Comparative analysis, distribution, and characterization of microsatellites in Orf virus genome. Sci Rep. 2020;10(1):13852. doi:10.1038/ s41598-020-70634-6

78. Chan K-W, Hsu W-L, Wang C-Y, et al. Differential diagnosis of orf viruses by a single- step PCR. J Virol Methods. 2009;160 (1):85-89. doi:10.1016/j.jviromet.2009.04.025

79. Margaret R, Ayman AH Orf. 2019. Available from: https://www. pathologyoutlines.com/topic/skinnontumororf.html Accessed September 7, 2020.

80. Hoover A, Milroy M Orf treatment \& management: medical care, surgical care, prevention.2019. https://emedicine.medscape.com/ article/1133450-treatment Accessed September 22, 2020.

81. Wang G, Yanhua W, Qi J, et al.. Comparison of the sensitivity of three cell cultures to ORFV. 2019:8.

82. Wang X, Zhang J, Hao W, et al. Isolation and characterization of monoclonal antibodies against a virion core protein of orf virus strain NA1/11 as potential diagnostic tool for orf viruses. Monoclon Antib Immunodiagn Immunother. 2015;34(4):233245. doi:10.1089/mab.2014.0101

83. Ivanov L, Hristov M, Peshev R. STUDIES ON CULTURAL CHARACTERISTICS OF CONTAGIOUS ECTHYMA (ORF) VIRUS. Bulg $J$ Vet Med. 2016;19(4):308-316. doi:10.15547/ bjvm.933

84. Scagliarini A, Gallina L, Dal Pozzo F, et al. Diagnosis of orf virus infection in humans by the polymerase chain reaction. New Microbiol. 2004;27(4):403-405.

85. Wang G, Shang Y, Wang Y, Tian H, Liu X. Comparison of a loopmediated isothermal amplification for orf virus withquantitative real-time PCR. Virol J. 2013;10(1):138. doi:10.1186/1743-422X$10-138$

86. Tsai S-M, Chan K-W, Hsu W-L, Chang T-J, Wong M-L, Wang CY. Development of a loop-mediated isothermal amplification for rapid detection of orf virus. J Virol Methods. 2009;157(2):200204. doi:10.1016/j.jviromet.2009.01.003

87. Degraeve C, De Coninck A, Senneseael J, Roseeuw D. Recurrent contagious ecthyma (Orf) in an immunocompromised host successfully treated with cryotherapy. Dermatology (Basel). 1999;198(2):162-163. doi:10.1159/000018095

88. Barraviera SRCS. Diseases caused by poxvirus - orf and milker's nodules: a review. J Venomous Animals Toxins Including Trop Dis. 2005;11(2):102108. doi:10.1590/S1678-9199200 5000200002

89. Rørdam OM, Ø G, Spigset O, Ryggen K. Giant orf with prolonged recovery in a patient with psoriatic arthritis treated with etanercept. Acta Derm Venereol. 2013;487-488. doi:10.2340/ 00015555-1514

90. Caravaglio JV, Khachemoune A. Orf virus infection in humans: a review with a focus on advances in diagnosis and treatment. $J$ Drugs Dermatol. 2017;16(7):684-689.

91. Ü G, Günde S, Melek Ü. Human Orf: echtyma contagiosum report of five cases. Turk J Med Sci. 2002;32(2):3.

92. Kilic SS, Puel A, Casanova J-L. Orf infection in a Patient with Stat1 gain-of-function. J Clin Immunol. 2015;35(1):80-83. doi:10.1007/s10875-014-0111-7

93. Uluğ M. A viral infection of the hands: orf. Jmid. 2013;03 (01):41-44. doi:10.5799/ahinjs.02.2013.01.0078

94. Anon. Imiquimod - an overview | scienceDirect Topics. Cancer Immunother. 2016. Available from: https://www.sciencedirect. com/topics/medicine-and-dentistry/imiquimod..

95. Ertekin SS, Gurel MS, Erdemir AVT, Leblebici C. Systemic interferon alfa injections for the treatment of a giant orf. Cutis. 2017;99(5):E19-E21.

96. Nfi A. Soremouth in sheep and goats at the Mankon Animal Research Station, Cameroon. Revue Elev Méd vét Pays trop. 1991;44(2):2. 
97. Africa. HANDISTATUS II Multiannual animal disease status. 2004. Available from: https://web.oie.int/hs2/sit_mald_freq_pl. asp?c_cont=1\&c_mald=152 Accessed October 26, 2020.

98. Hasheminasab SS, Mahmoodi A, Mahmoodi P, Maghsood H. Orf virus infection in human ecthyma contagiosum: a report of two cases in the West of Iran. Virusdisease. 2016;27(2):209-210. doi:10.1007/s13337-016-0304-1

99. Scagliarini A, Piovesana S, Turrini F, Savini F, Sithole F, McCrindle CM. Orf in South Africa: endemic but neglected. Onderstepoort $J$ Vet Res. 2012;79(1):8. doi:10.4102/ojvr. v79i1.499

100. Saade D, Higham C, Vashi N. A case series of orf infection after the religious sacrifice feast Eid al-Adha. JAAD Case Rep. 2018;4 (5):489-492. doi:10.1016/j.jdcr.2018.01.007

101. Ozkan B, Uysal CA, Uner H, Ertas NM. Sacrifice feast disease: orf. Turkish J Plastic Surg. 2020;28(3):195. doi:10.4103/tjps. tjps_73_19

102. Bala JA, Balakrishnan KN, Abdullah AA, et al. An association of Orf virus infection among sheep and goats with herd health programme in Terengganu state, eastern region of the peninsular Malaysia. BMC Vet Res. 2019;15(1):250. doi:10.1186/s129170191999-1

103. Arens M. Methods for Subtyping and Molecular Comparison of Human Viral Genomes. Clin Microbiol Rev. 1999;12(4):612-626. doi:10.1128/CMR.12.4.612

104. Chi X, Zeng X, Hao W, et al. Heterogeneity among Orf Virus Isolates from Goats in Fujian Province, Southern China.. PLOS ONE. 2013;8(10):e66958. doi:10.1371/journal.pone.0066958

105. Bala JA, Balakrishnan KN, Abdullah AA. The re-emerging of orf virus infection: a call for surveillance, vaccination and effective control measures.. Microb Pathog. 2018;120:9. doi:10.1016/j. micpath.2018.04.057

106. Selim A, Elhaig M, Höche J, Gaede W. BMTW_Molecular detection and analysis of Sheeppox and Orf viruses isolated from sheep from Qalubia, Egypt. Berliner und Münchener Tierärztliche Wochenschrift. (Berliner und Münchener Tierärztliche Wochenschrift 129, Heft 7/8 (2016), Seiten 310-317). 2016;310-317. doi:10.2376/0005-936615076
107. Mwanandota J, Macharia M, Car. M-N, Sallu R, Yongolo M, Holton T. Phylogenetic Analysis of ORF virus from goats in Tanzania: short communication. Universal Journal of Agricultural Research. 2016;4(5):165-169. doi:10.13189/ ujar.2016.040501

108. Munz E, Schillinger D, Reimann M, Mahnel H. Electron Microscopical Diagnosis of Ecthyma contagiosum in Camels (Camelus dromedarius) First Report of the Disease in Kenya. $J$ Vet Med Series B. 1986;33(1-10):73-77. doi:10.1111/j.14390450.1986.tb00007.x

109. Simulundu E, Mtine N, Kapalamula TF, et al. Genetic characterization of orf virus associated with an outbreak of severe orf in goats at a farm in Lusaka, Zambia (2015). Arch Virol. 2017;162 (8):2363-2367. doi:10.1007/s00705-017-3352-y

110. Mahmoud M, Abdelrahman K, Soliman H. Molecular and virological studies on contagious pustular dermatitis isolates from Egyptian sheep and goats. Res Vet Sci. 2010;89(2):290-294. doi:10.1016/j.rvsc.2010.02.019

111. Mombeni EG, Mousavi MB, Ranjbaran I, et al.. Prevention and treatment of contagious ecthyma in sheep and goat by goat-pox vaccine in Khuzestan Province, Iran. 2012;1:4

112. Demiraslan H, Doganay GD . An Overwiev of ORF Virus Infection in Humans and Animals. Recent Patents on AntiInfective Drug Discovery. 2017. Accessed October21, 2020. https://www.eurekaselect.com/152874/article

113. Bass JM Human Orf Virus Infection from Household Exposures — united States, 2009-2011. 2012. Available from: https://www. cdc.gov/mmwr/preview/mmwrhtml/mm6114a3.htm Accessed September 28, 2020.
Research and Reports in Tropical Medicine

\section{Publish your work in this journal}

Research and Reports in Tropical Medicine is an international, peerreviewed, open access journal publishing original research, case reports, editorials, reviews and commentaries on all areas of tropical medicine, including: Diseases and medicine in tropical regions; Entomology; Epidemiology; Health economics issues; Infectious disease; Laboratory science and new technology in tropical medicine;

\section{Dovepress}

Parasitology; Public health medicine/health care policy in tropical regions; and Microbiology. The manuscript management system is completely online and includes a very quick and fair peer-review system. Visit http://www.dovepress.com/testimonials.php to read real quotes from published authors. 